\title{
Calculation Method of Short Duration Rainstorm Intensity Formula Considering Non-Stationarity of Rainfall Series: Impacts on Simulation of Urban Drainage System
}

\author{
Zening Wu \\ Zhengzhou University \\ Shifeng Liu \\ Zhengzhou University \\ Huiliang Wang ( $\nabla$ wanghuiliang@zzu.edu.cn ) \\ Zhengzhou University https://orcid.org/0000-0003-0057-455X
}

\section{Research Article}

Keywords: Rainstorm intensity formula, Short duration, Nonstationarity, GAMLSS, Mike Flood, Urban drainage system

Posted Date: March 11th, 2021

DOI: https://doi.org/10.21203/rs.3.rs-307245/v1

License: (c) (1) This work is licensed under a Creative Commons Attribution 4.0 International License. Read Full License 


\title{
Calculation method of short duration rainstorm intensity formula considering non-stationarity of rainfall series: impacts on simulation of urban drainage system
}

\author{
Zening wu, Shifeng Liu, Huiliang Wang*
}

College of Water Conservancy Engineering, Zhengzhou University, Zhengzhou,

\section{Henan 450001, PR China}

\begin{abstract}
The changing nature of the earth's climate and rapid urbanization lead to the change of rainfall characteristics in urban areas, and the stability of rainfall series is destroyed, it is a difficult challenge to consider this change in urban drainage simulation. A variety of methods are used to test the stationarity of annual maximum rainfall intensity series of Zhengzhou meteorological station from 1981 to 2010, and the intensity-duration-frequency (IDF) curves of changing environment are fitted by
\end{abstract} GAMLSS model and further generalized into short duration rainstorm intensity formula. The 3-hour design rainstorm in different scenarios was used as the input of Mike Flood model to simulate the operation of the campus drainage system of Zhengzhou University. Results indicated that: The rainfall series is non-stationary and has an increasing trend. Although the parameters of the short duration rainstorm intensity formula have no fixed change rules, there are traces to follow in the design rainstorm. According to Mike Flood model, the non-stationary scenario provides a series of dangerous signals such as more flood volume, larger inundation area, higher

\footnotetext{
* Corresponding author at: College of Water Conservancy Engineering, Zhengzhou University, Zhengzhou, Henan 450001, PR China

E-mail address: wanghuiliang@zzu.edu.cn (H. Wang).
} 
flood depth and slower recession process. The flood volume of the non-stationary scenario is $23.5 \%$ more than that of the stationary scenario, and the inundated area is $18.5 \%$ more when the return period is 5 years. In the future, the difference is $34.0 \%$ and $24.6 \%$ respectively, and it can reach more than $50 \%$ when the return period is once in two years. We will discuss the non-stationarity and challenges brought about by changing environments.

Keywords: Rainstorm intensity formula, Short duration, Nonstationarity, GAMLSS, Mike Flood, Urban drainage system

\section{Introduction}

Urban drainage system is the main engineering system of urban sewage and rainwater transportation and drainage. It is the infrastructure to protect the city from flood damage. There are many impervious areas on the urban surface, and the natural rivers and lakes have been transformed. On the one hand, the rainfall interception and infiltration amount are significantly reduced, and the net rainfall is increased; on the other hand, the convergence speed is obviously accelerated. Once the rainstorm exceeds the design standard of drainage system, waterlogging disaster is likely to occur in the city, causing incalculable loss and harm (Zheng et al., 2016; Anker et al., 2019; Abass et al., 2020). In recent years, the impact of global urban waterlogging has been intensified, and the frequency and degree of urban flood are increasing (Douglas et al., 2008; Kundzewicz et al., 2014). At present, the design of urban drainage system depends on the intensity and frequency of historical extreme heavy rainfall, which is 
usually summarized as IDF curves or further generalized into the form of rainstorm intensity formula. The existing infrastructure is generally designed by static rainstorm intensity formula. It is assumed that the environment formed by rainstorm does not change and the probability density of hydrological variables does not change with time, which shows that the statistical characteristics do not change ( $\underline{\text { Strupczewski et }}$ al., 2001; Milly et al., 2008; Salles et al., 2019). However, the fifth assessment report of the Intergovernmental Panel on climate change of the United Nations (IPCC AR5) pointed out that the intensity and frequency of Rainstorm in most land areas of the world may increase due to the impact of global climate change and land use change. This means that the existing hydrological steady-state law has been broken, and the rainstorm intensity formula relying on the assumption of stationarity may underestimate the extreme rainfall events, which will bring unnecessary losses if applied to the design of urban drainage system (Khaliq et al., 2006; Willems et al., 2012; Forzieri et al., 2018). In addition, some studies have shown that with the increase of research time, the deviation of non-stationary and stationary design values will be larger and larger(Agilan and Umamahesh,2016; Lima et al., 2018; Hosseinzadehtalaei et al., 2020). Therefore, it is necessary to explore the non-stationary rainstorm intensity formula and its impacts on simulation of urban drainage system to provide theoretical basis for urban drainage system design.

Since 1901 , the global average temperature has increased by $0.89{ }^{\circ} \mathrm{C}$, which has seriously affected the precipitation pattern, and this trend has become more obvious in recent years (Banerjee et al.,2020). On the one hand, global warming accelerates the 
process of global hydrological cycle and regional hydrological cycle, which increases the probability of rainfall occurrence; on the other hand, the increase of temperature leads to the increase of atmospheric water holding capacity, which may lead to greater rainfall intensity. (Wang et al., 2017; Yaduvanshi et al.,2020) In addition, due to the urban heat island effect brought by urbanization and more abundant condensation nuclei caused by a large number of particles in urban areas, the intensity of extreme rainstorm in urban areas has increased significantly (Li et al., 2019; Liu and Niyogi, 2020). The rainfall patterns of many cities in the world have been studied extensively.

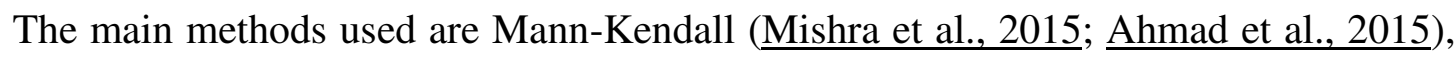
Spearman (Rahman et al., 2017), Linear regression (Yurekli, 2020) and so on. Although the short duration rainstorm has obvious change trend, it is not necessarily reflected in the long-term rainstorm( Madsen et al., 2009; Rosenberg et al., 2010; Fujibe, 2013; Zhou et al., 2017). It is worth mentioning that the short duration rainstorm is one of the main causes of urban waterlogging. There are a lot of impervious surface on the urban surface, less rainfall interception and infiltration, and the urban surface roughness is small. The natural river channel is transformed into an artificial river channel with fast convergence speed (Chen et al., 2015; Bertilsson et al., 2019; Pour et al., 2020). Urban drainage system is very sensitive to short duration rainstorm, so it is necessary to focus on the non-stationary short duration rainstorm intensity formula and its impacts on simulation of urban drainage system.

Many methods have been used to derive the return period values of non-stationary hydrological time series (Coulibaly et al., 2005; Cheng et al., 2014; 


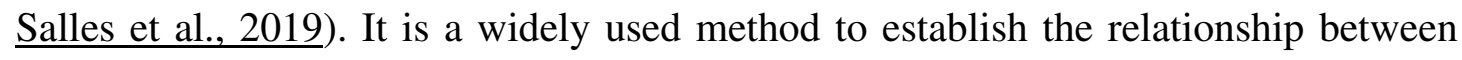
the distribution function of time series and the explanatory variables ( $\underline{\text { Salas and }}$ Obeysekera, 2014; Balistrocchi and Grossi, 2020). GAMLSS model has become an important tool for hydrological extreme value time series analysis because of its good flexibility and adaptability (Villarini et al., 2009; Villarini and Serinaldi, 2012; $\underline{\text { Hao et }}$ al., 2019). GAMLSS model has shown excellent performance in the frequency

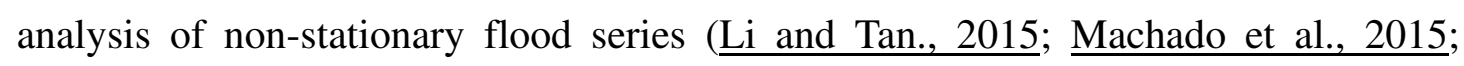
Debele et al., 2017a; Zhang et al., 2018), but there is little research on its application to short duration rainstorm intensity formula.

In recent years, many researchers have analyzed the impact of environmental change on extreme rainstorm and urban drainage system (Denault et al., 2006; Arnbjerg-Nielsen et al., 2013; Huong and Pathirana, 2013; Zhang et al., 2019; Xiong et al., 2019; Andimuthu et al., 2019; Yang et al., 2020).It is found that under the non-stationary conditions and future environment, the risk of damage to the existing drainage system infrastructure will increase. The change of short duration rainstorm will have a significant impact on the outflow, overload and overflow of urban drainage system. Unfortunately, most studies have not carried out a full and detailed impact analysis of urban drainage system, such as the flooded area, the maximum flooded depth, the risk bearing pipeline and node, the detailed inundation process, etc.

The contribution of urban short duration rainstorm characteristics caused by climate change and urbanization to urban flood risk can not be ignored. Taking Zhengzhou University campus as an example, this paper establishes Mike urban 
model of one-dimensional urban drainage network and Mike 21 model of planar two-dimensional free surface flow. Through Mike Flood, the dynamic coupling of the two models is realized to complete the detailed evaluation of the operation of urban drainage system. The influence of non-stationarity on short duration extreme rainstorm is reflected by GAMLSS model. This work is helpful to better understand the non-stationarity of short duration extreme rainstorm under changing environment and its impact on urban drainage system, and provide technical support for the design and reconstruction of urban drainage system in the study area. The main research contents are as follows: (1) to study whether the characteristics of short duration rainstorm have changed and its change trend; (2) to study the development of non-stationary short duration rainstorm intensity formula under changing environment; (3) to study the influence of short duration rainstorm intensity formula on simulation of urban drainage system under different scenarios.

\section{Material and methods}

\subsection{Study area and data}

Zhengzhou University campus, located at $113^{\circ} 39^{\prime \prime} \mathrm{E}$ and $34^{\circ} 47^{\prime \prime} \mathrm{N}$, is located in the continental monsoon climate zone of north temperate zone, with four distinct seasons. The annual average precipitation is between $600 \mathrm{~mm}$ and $700 \mathrm{~mm}$, and the rainfall from June to September accounts for more than $50 \%$ of the annual rainfall. In recent years, with the development of climate change and urbanization, urban flood occurs almost every year. Although the local government has actively expanded and 
reconstructed the urban drainage system, the situation is not optimistic.

This study mainly uses the observed IDF data of Zhengzhou meteorological station from 1981 to 2010 , including 11 annual maximum rainfall series with different rainfall duration (from 5 minutes to 180 minutes) and the actual observed rainfall data on August 12, 2017. Zhengzhou meteorological station is very close to the study area, its rainfall characteristics can represent the characteristics of Rainstorm in the study area. In addition, the basic data used in the study include the urban drainage network planning map of shp format from Zhengzhou University logistics office, including 369 pipelines and a drainage outlet (Fig. 1b). The digital elevation map (DEM) is obtained by Kriging interpolation based on discrete elevation points (Fig. 1a). Before interpolation, we correct the elevation of some abnormal points. According to the remote sensing image map, the land use types can be divided into four types: buildings, roads, greenbelt and waters (Fig. 1c).
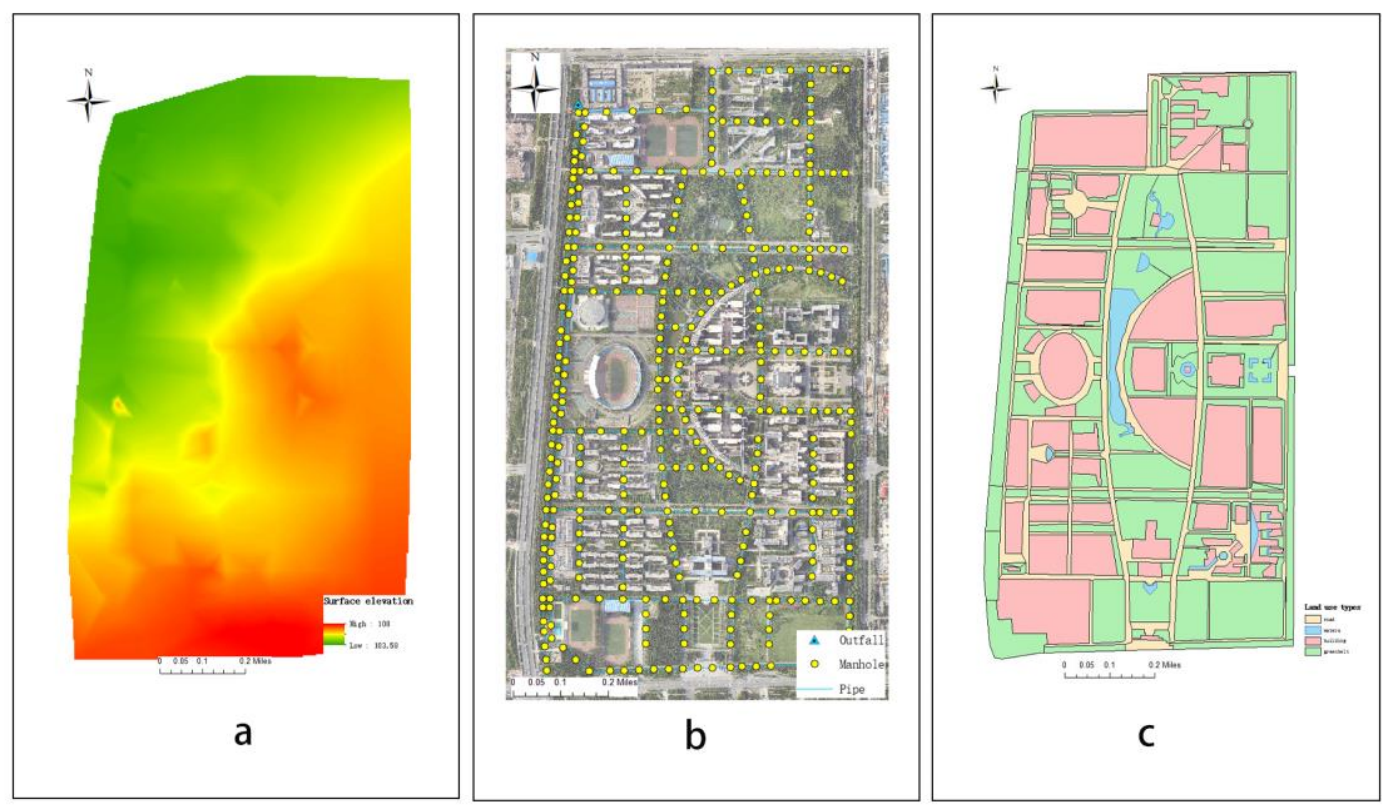

Fig. 1 (a) DEM of the study site; (b) drainage system of the study site; (c) land 


\section{use types}

\subsection{Stationarity tests}

The stationarity tests of rainstorm data mainly include the test of trend, mutation and periodicity. Mann-Kendall trend test is a non-parametric statistical test method, which does not require samples to follow a certain distribution and is not affected by a few outliers. It has been widely used in the analysis of time series of rainfall, runoff, temperature and other factors. In addition, non-parametric Spearman rank correlation test, Kendall trend test, least squares linear regression (parametric Pearson linear test), Theil Sen estimation, moving average method are commonly used to test the trend of rainstorm series. The commonly used methods to test the variability of hydrological series include non-parametric Pettitt test, sliding t test, ordered clustering method and so on.

\subsection{GAMLSS model}

$\underline{\text { GAMLSS }}$ is a kind of (semi) parametric regression model (Rigby and

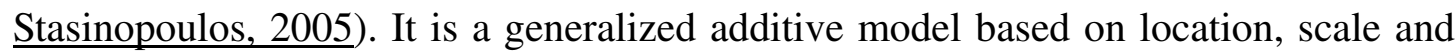
shape parameters developed by Rigby and Stasinopoulos in order to overcome the limitations of correlation models such as generalized linear model and generalized additive model. GAMLSS model can extend the distribution of original sequence samples from normal distribution and exponential distribution family to more distribution families, so as to adapt to more complex and extensive data set fitting. 
Moreover, GAMLSS allows to describe the linear and nonlinear relationship between statistical parameters and covariates, which makes GAMLSS have obvious advantages in dealing with nonuniform frequency analysis. The model is transformed into the traditional stationary model when the parameters of probability distribution function are constant.

In this study, the position parameters and scale parameters corresponding to the mean and variance are analyzed, and the covariant is time t. There may be large error if only linear trend is used to simulate non-stationary series (Agilan and Umamahesh, 2017). In this paper, we also use the maximum polynomial of degree 3 to study the distribution of covariates. Four commonly used two parameter distribution functions are selected: Gumbel (GU), Gamma (GA), Lognormal (LOGNO) and Weibull (WEI).On this basis, seven models are set up: (a) $\theta_{1}$ and $\theta_{2}$ are both invariant; (b) $\theta_{1}$ is invariant, $\theta_{2}$ is linear function of time; (c) $\theta_{1}$ is linear function of time, $\theta_{2}$ is invariant; (d) $\theta_{1}$ and $\theta_{2}$ are both linear functions of time; (e) $\theta_{1}$ is invariant, $\theta_{2}$ is polynomial function of time; (f) $\theta_{1}$ is polynomial function of time, $\theta_{2}$ is invariant; (g) $\theta_{1}$ and $\theta_{2}$ are both polynomial functions of time. AIC and SBC criteria were used to compare the goodness of fit.

\subsection{Mike Flood hydrodynamics model}

In this study, Mike Flood (DHI user guide, 2017) integrated hydrological and hydrodynamic model is used to simulate the operation of the campus drainage system and the surface hydrodynamic process of Zhengzhou University. Mike Flood is a 
dynamic coupling model system developed by DHI (Danish Hydrological Research Institute). It can simulate drainage network, river channel, open drainage channel, various hydraulic structures and 2D slope flow at the same time. It has been very mature in urban flood simulation. The modules used in this study are Mike urban one-dimensional underground pipe network model and Mike 21 two-dimensional free surface flow model, which are coupled by Mike Flood platform.

In terms of pipe network hydrodynamic model, Mike urban adopts Saint Venant equations (continuity equation and momentum equation) of one-dimensional free surface flow, and uses Abbott-Ionescu six point implicit scheme finite difference method to solve the problem.In the aspect of two-dimensional surface flow simulation, Mike 21 uses the implicit finite difference method to solve the two-dimensional unsteady flow equations.

The DEM data is transformed into the dfs2 format that can be used, and the buildings and roads are superimposed to represent the complex terrain of urban areas. The runoff flows into the drainage system through the connected nodes. When the drainage capacity of the drainage system is exceeded, the flood will overflow to the surface and form submergence.

The model can be set to operate under various boundary conditions (such as rainfall runoff, external input flow, etc.) In this model, only the rainfall time series (dfs0 format) is used as the boundary condition to analyze the operation of drainage system under different short duration design rainfall conditions. 


\section{Results}

\subsection{Non-stationarity of short duration rainstorm series}

The data period of Zhengzhou meteorological station is 1981-2010, including 11 annual maximum rainfall intensity series with different rainfall duration (5min, 10min, $15 \mathrm{~min}$, 20min, 30min, 45min, 60min, 90min, 120min, 150min, 180min). The original data of each sequence and the five-year moving average are plotted in the same coordinate system (Fig. 2a-k). After about 1995, the moving average of all sequences is larger than that of the whole series, and there is an increasing trend. In addition, the time range is divided into three periods: 1981-1990, 1991-2000 and 2001-2010, each of which is 10 years. The average value of each period is calculated and plotted (Fig. 21). It can be seen from the figure that with the increase of time, the average rainfall intensity increases, and with the increase of rainfall duration, the average rainfall intensity gradually decreases, and the gap between different periods is also becoming smaller and smaller. In view of this, we preliminarily believe that these sequences may be non-stationary and have a trend of increasing gradually. 


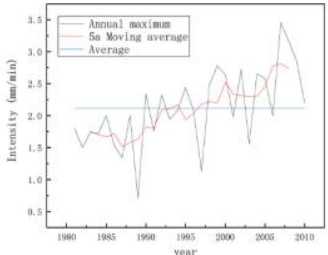

a

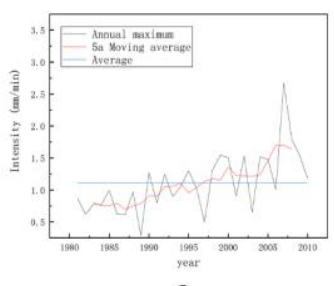

e

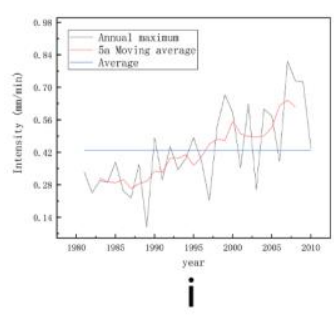

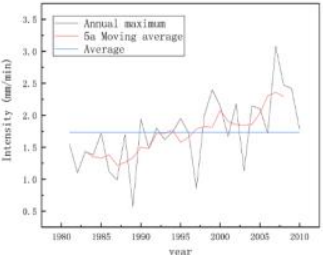

b

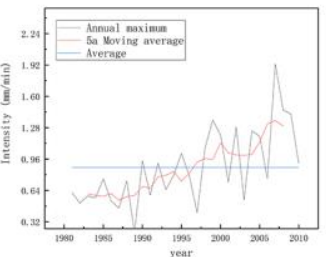

f

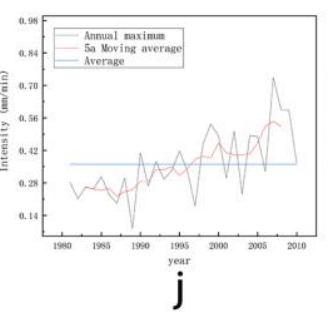

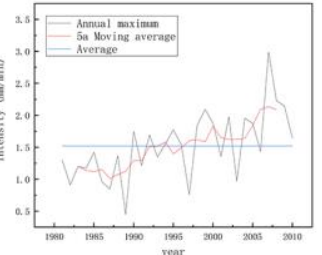

C

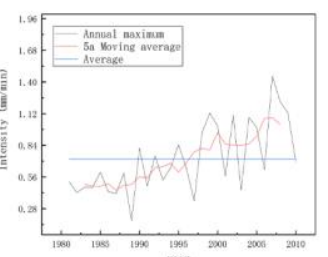

g

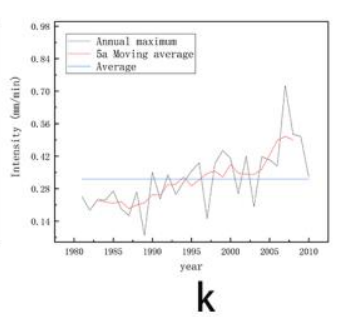

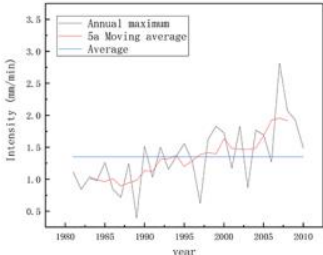

d

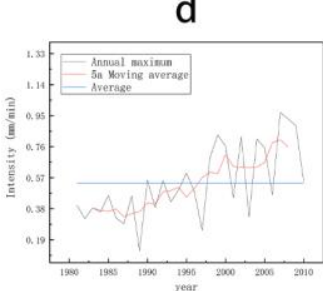

$\mathrm{h}$

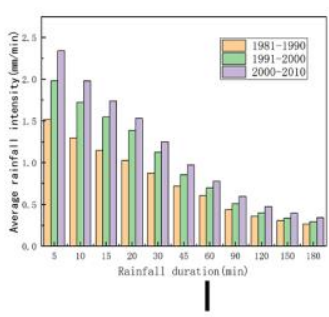

Fig. 2 (a - k) show the sequence value of annual maximum rainfall intensity and five-year moving average value of rainfall duration from 5 - $180 \mathrm{~min}$. (l)is the bar chart of ten-year average value of maximum rainfall intensity in different rainfall periods

In order to fully prove the non-stationarity and verification trend of short duration rainstorm series, we used Spearman rank method, Kendell rank method and linear regression method to test under the condition of significance level of 0.05 (Table. 1). When the significance level is 0.05 , the time series with rainfall duration of 5min, $10 \mathrm{~min}, 15 \mathrm{~min}$ and $20 \mathrm{~min}$ have significant non-stationarity in the three test methods, and the test values of other sequences are also close to the critical value. In the linear regression test method, except for the 60 min sequence, all the time series show significant non-stationarity. 
Table. 1 table of stationarity test results; the red font in the table indicates that the non-stationarity is significant

\begin{tabular}{ccccccccccccc}
\hline Method & 5 & 10 & 15 & 20 & 30 & 45 & 60 & 90 & 120 & 150 & 180 \\
\hline Spearman & 4.71 & 3.31 & 2.81 & 2.69 & 1.83 & 1.64 & 1.43 & 1.83 & 1.56 & 1.46 & 1.42 \\
Kendell & 3.69 & 2.98 & 2.66 & 2.56 & 1.73 & 1.62 & 1.55 & 1.87 & 1.73 & 1.59 & 1.41 \\
Linear & & & & & & & & & & & \\
Regression & 4.51 & 3.39 & 2.89 & 2.77 & 2.06 & 1.74 & 1.32 & 1.79 & 1.78 & 2.01 & 1.72 \\
\hline
\end{tabular}

In order to further understand the trend of the sequence and identify the mutation, Mann - Kendall test was conducted at the significance level of 0.05 (Fig. 3). UF values of all sequences are greater than 0 and remain above 0 after the 1990s. The original sequence has a trend of increasing gradually, and this trend is significant in individual sequences. In the critical value range, all sequences have the crossing point of UF and UK, which means that the original sequence may have mutation besides trend. 


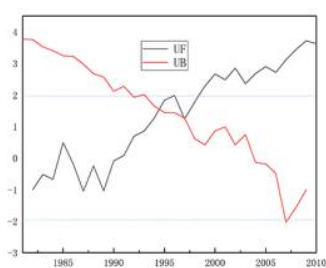

$5 \mathrm{~min}$

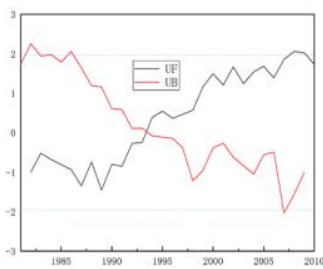

$30 \mathrm{~min}$

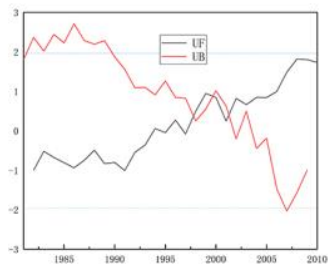

$120 \mathrm{~min}$

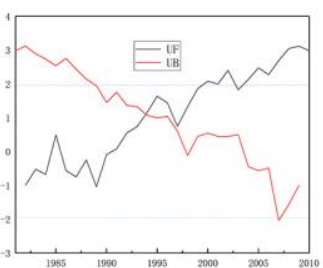

$10 \min$

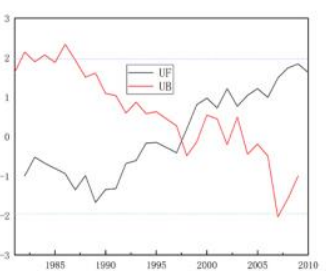

$45 \mathrm{~min}$

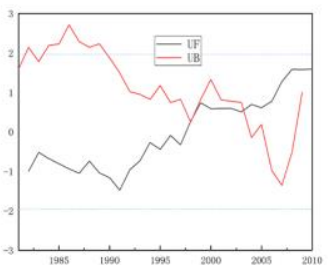

$150 \mathrm{~min}$

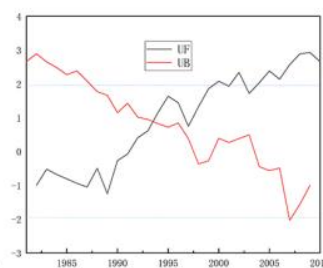

$15 \mathrm{~min}$

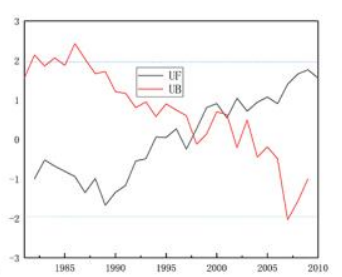

$60 \mathrm{~min}$

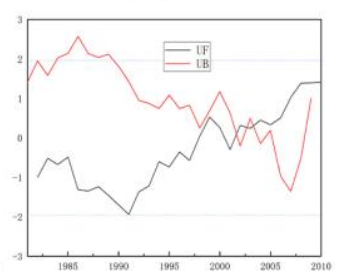

$180 \mathrm{~min}$

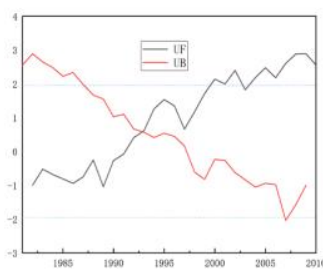

$20 \mathrm{~min}$

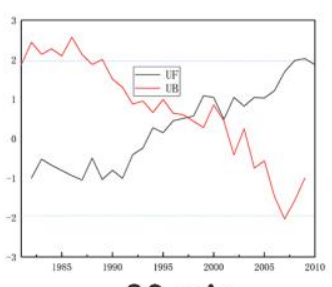

$90 \min$

Fig. 3 Mann - Kendall test results of annual maximum rainfall intensity series for each rainfall duration. (significance level is 0.05 )

In a word, the short duration rainstorm sequence has changed, which can not meet the requirements of stability. It is unreasonable to continue to plan and design urban drainage system under the assumption of stationarity. It is necessary to calculate the short duration IDF curves and rainstorm intensity formula in the case of non-stationary, and consider the impact of these variations on the urban drainage system in the future.

\subsection{Rainstorm intensity formula under changing environment}

\subsubsection{Evaluation of GAMLSS goodness of fit}

According to AIC and SBC criteria, the variation of annual maximum rainfall 
intensity sequence with rainfall duration of $5 \mathrm{~min}$ can be simulated by GU, and other sequences using WEI is better. At the same time, it is better to select the model that the annual maximum rainfall intensity sequence with rainfall duration of 5 minutes and is a linear function of time, while the model with only linear change with time is more suitable for other series. The fact shows that although we consider the influence of nonlinear link function, but for the data of this study, the linear function performs well and can achieve good simulation effect.

\subsubsection{Residual analysis of GAMLSS model}

In the standard residual normal QQ (Quantile - Quantile Plot) chart (Fig. 4), the scatter distribution is close to 1:1 straight line; in the residual normal worm chart (Fig. 5), the scatter points are distributed in the $95 \%$ confidence interval of the confidence level and close to the red curve. This shows that the model fitting effect is good. 


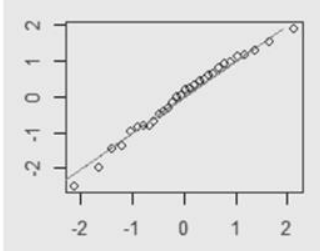

$5 \mathrm{~min}$

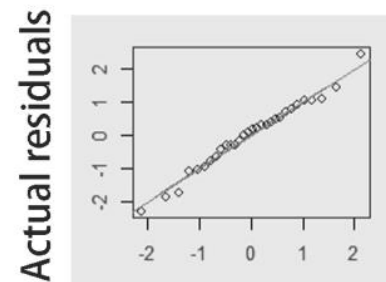

$30 \mathrm{~min}$

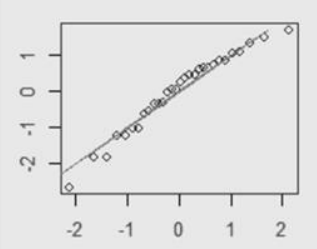

$120 \mathrm{~min}$

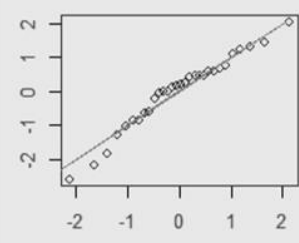

$10 \mathrm{~min}$

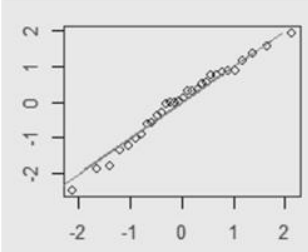

$45 \mathrm{~min}$

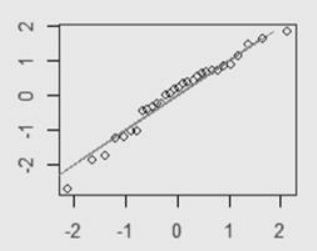

$150 \mathrm{~min}$

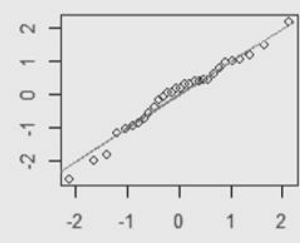

$15 \mathrm{~min}$

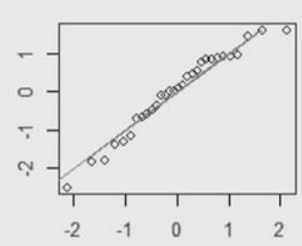

$60 \mathrm{~min}$

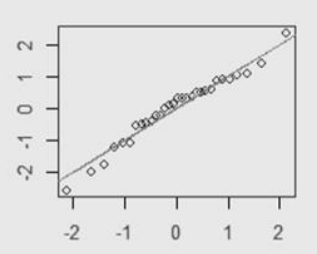

$180 \mathrm{~min}$

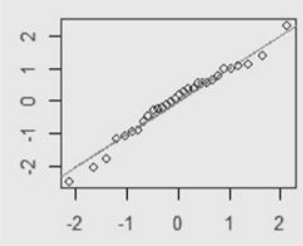

$20 \mathrm{~min}$

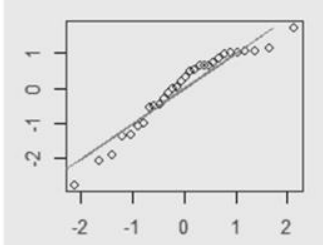

$90 \mathrm{~min}$

Theoretical residuals

Fig. 4 Standard normal QQ chart based on selected GAMLSS model regression analysis
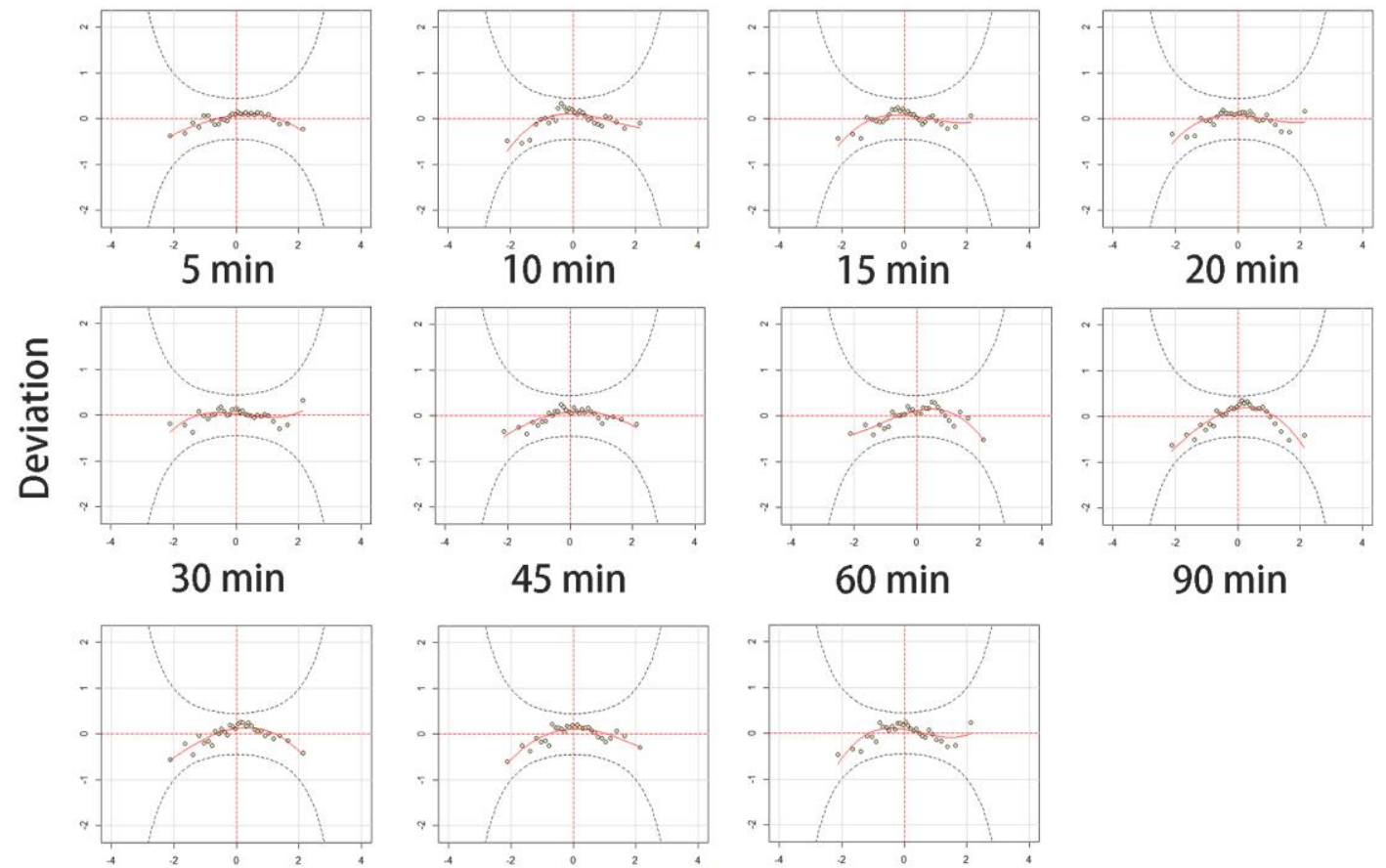

$120 \mathrm{~min}$

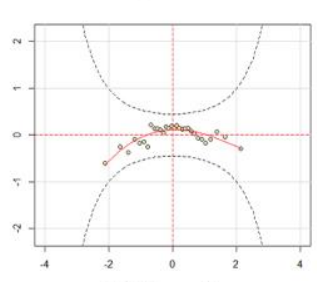

$150 \mathrm{~min}$

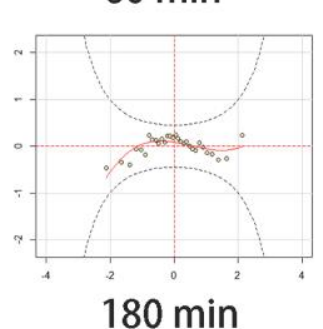

Unit normal quantile 
Fig. 5 Residual normal worm chart based on regression analysis of selected

\section{GAMLSS model}

\subsubsection{Rainstorm intensity formula under changing environment}

According to the fitting results of gamlss model, the quantile curves are summarized and predicted, and the design value curves of different return periods are obtained (Fig. 6). It can be seen from the figure that although the change range is not consistent, the annual maximum rainfall intensity series change is mainly increased, and this trend may be more obvious in the future. For convenience, we use (a) to represent the scenario of non-stationarity in the past 1981, (b) the current situation of non-stationarity in 2020, (c) the scenario of non-stationary in the future 2030, (d) the scenario of stationary assumption. The design values are plotted on the double logarithmic coordinate paper together with the design results (Fig. 7). 

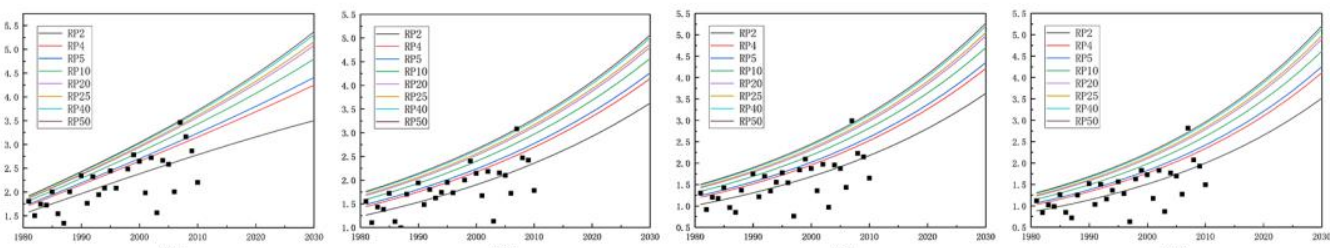

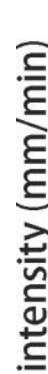

$10 \mathrm{~min}$

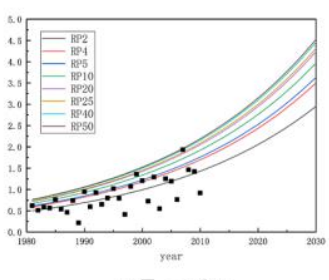

$45 \mathrm{~min}$

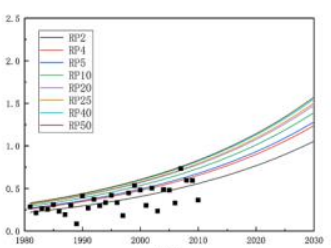

$150 \mathrm{~min}$
$15 \mathrm{~min}$

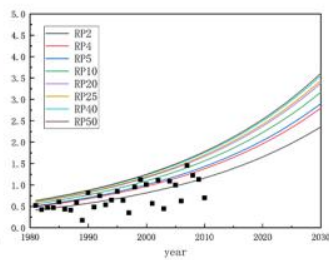

$60 \mathrm{~min}$

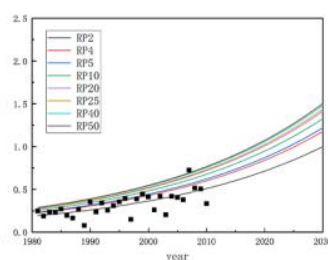

$180 \mathrm{~min}$
$20 \mathrm{~min}$

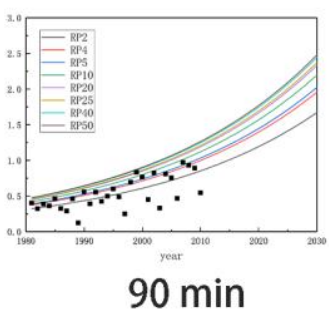

$120 \min$

curves of annual maximum rainfall intensity based on selected GAMLSS model
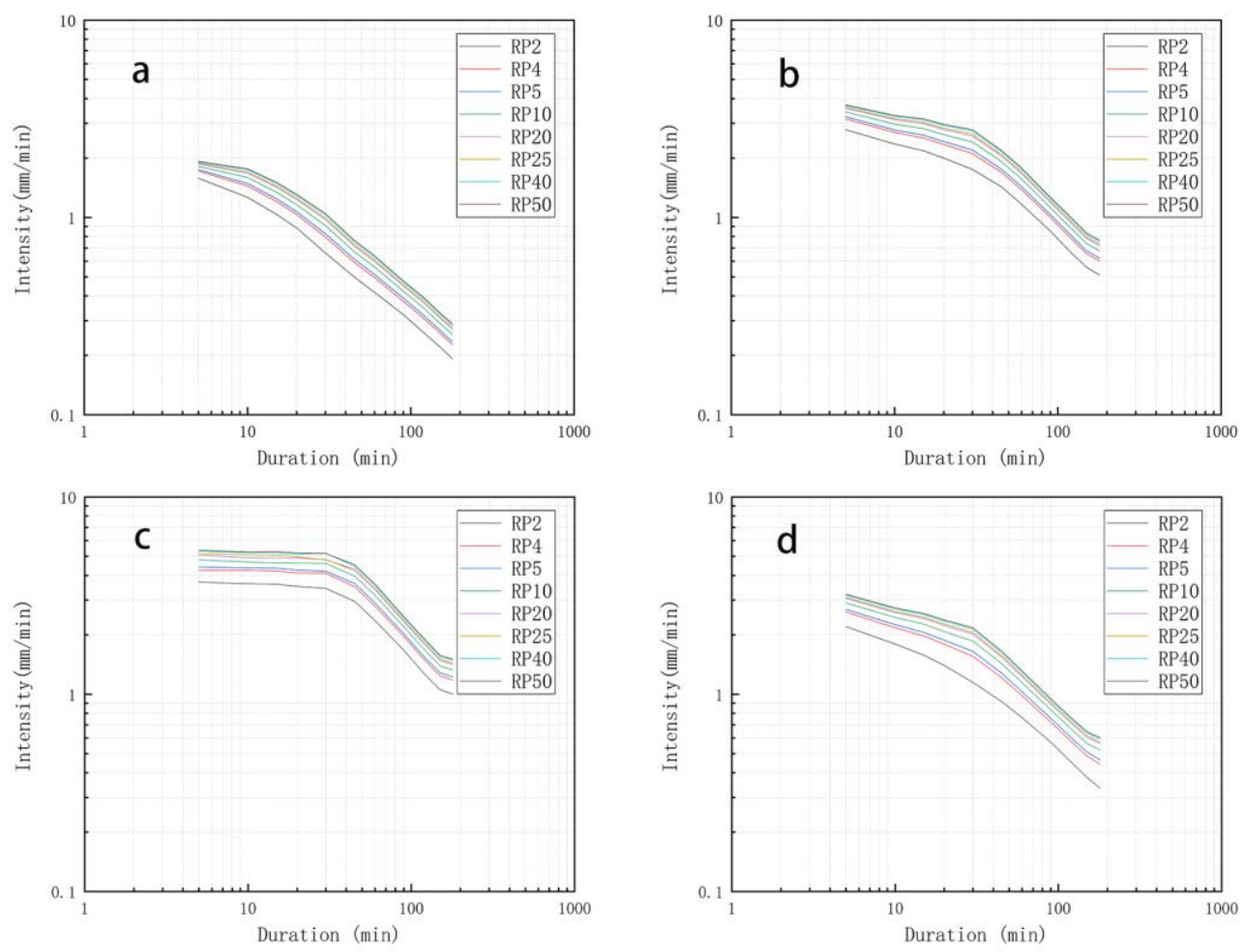
Fig. 7. IDF curves under different scenarios; a (non-stationary past level - 1981); b (non-stationary current level - 2010); c (non-stationary future level - 2030); d (stationary hypothesis IDF curves)

All IDF curves are slightly downward curved in the double logarithmic coordinate paper. The corresponding rainstorm intensity formula is used to further summarize the IDF curves:

$$
i=\frac{167 A_{1}(1+C \lg P)}{(t+b)^{n}}
$$

Where: $t$ is rainfall duration, $b$ is time parameter, $n$ is attenuation index, $p$ is return period, $A_{1}$ and $C$ are proportional parameters.

The short duration rainstorm intensity formula suitable for the return period of 2 to 50 years is obtained by means of Marqurlt method. The parameter values of rainstorm intensity formula under four scenarios are shown in table 2.

Table. 2. Parameter values of rainstorm intensity formula under the four scenarios; a (non-stationary past level - 1981); b (non-stationary current level - 2010); c (non-stationary future level - 2030); d (stationary hypothesis parameter values)

\begin{tabular}{ccccc}
\hline scenario & $\mathrm{A}_{1}$ & $\mathrm{~b}$ & $\mathrm{C}$ & $\mathrm{n}$ \\
\hline $\mathrm{a}$ & 40.8 & 43.6 & 1.164 & 0.958 \\
$\mathrm{~b}$ & 80.0 & 35.2 & 0.684 & 1.034 \\
$\mathrm{c}$ & 58.4 & 30.0 & 0.633 & 0.982 \\
$\mathrm{~d}$ & 93.3 & 40.5 & 1.008 & 1.109 \\
\hline
\end{tabular}




\subsection{Design Rainstorm Process under changing environment}

We use the Chicago method to distribute rainfall, and take the rainfall peak coefficient of 0.5 to obtain the three-hour design rainstorm process of four scenarios (Fig .8). Compared with (d), the total precipitation of (a) is slightly higher, but the maximum peak intensity is significantly lower. Both the total rainfall and the peak intensity of (b) and (c) are higher than those of (d). The peak precipitation intensity of (b) is about $10 \%$ higher than that of (d), the total precipitation is increased by about $15 \%$, the peak precipitation intensity of (c) is about $20 \%$ higher than that of (d), and the total precipitation is also increased by $20 \%$. Generally speaking, the design rainstorm under non-stationary condition has higher peak value and rainfall than that under static assumption, especially the short-term rainfall change is more obvious, which means that the rainstorm is more concentrated and the urban drainage system is facing greater challenges. 

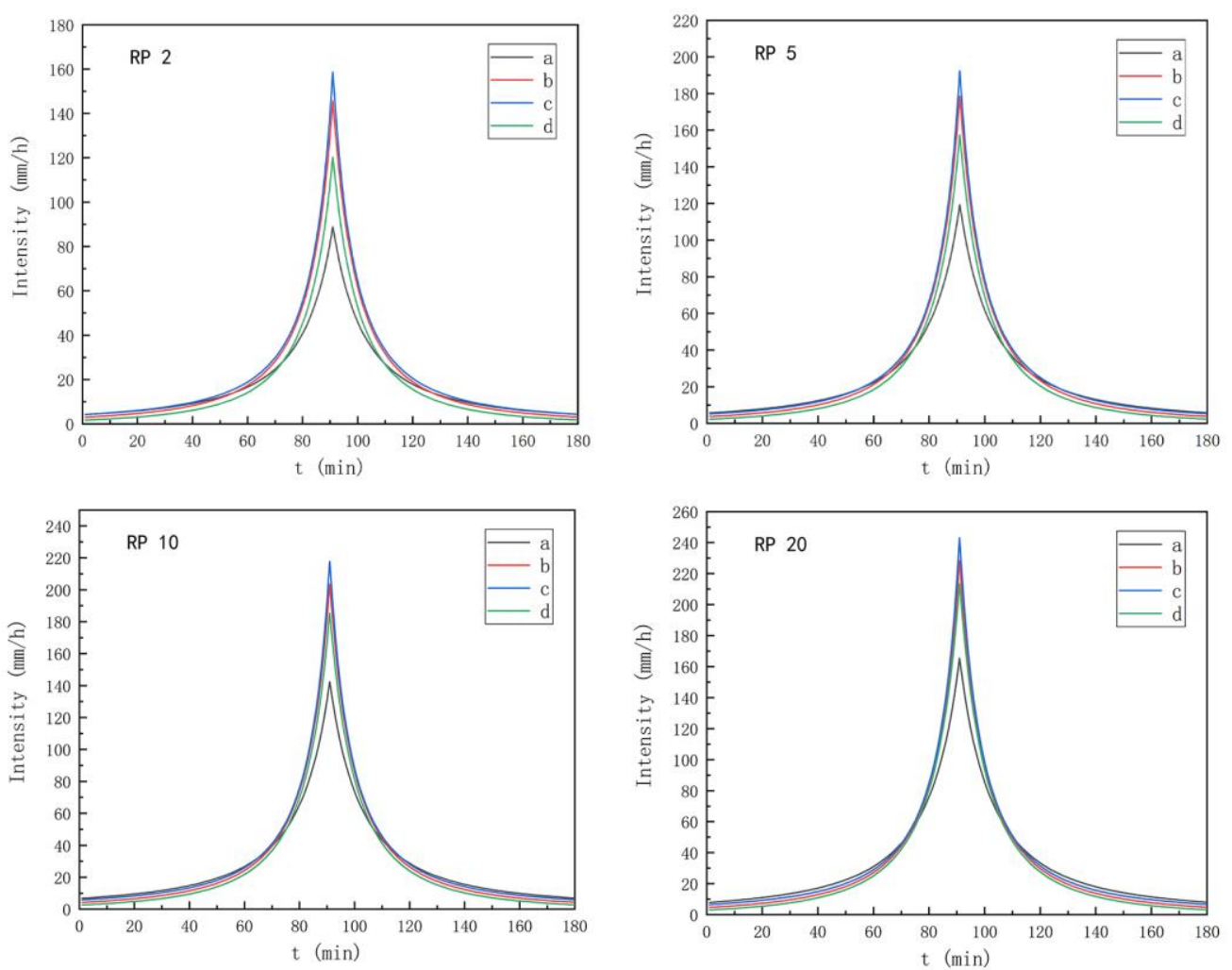

Fig. 8 Design rainstorm processes of the four scenarios; a (non-stationary past level - 1981); b (non-stationary current level - 2010); c (non-stationary future level - 2030); d (stationary hypothesis design rainstorm processes)

\subsection{Mike Flood simulation results}

\subsubsection{Validation model}

It is difficult to obtain the actual measured data of inundation area and time. Due to the lack of actual observation data of flood inundation, qualitative verification method is adopted to verify the model. It is indeed found that there was a waterlogging event on August 12, 2017, and the corresponding rainfall data with a 70 minute observation interval of 10 minutes from $14: 30$ to $15: 40$, with a total precipitation of $51 \mathrm{~mm}$ (close to the once-in-two-year rainfall). We simulated the event 
and compared it with the actual observation. The simulation results (Fig. 9 and Table. 3) show that the inundated area is $199275 \mathrm{~m}^{2}$, accounting for $6.86 \%$ of the total area of the study area(the study area in the model is $2903625 \mathrm{~m}^{2}$ ). Among them, the areas with serious inundation mainly include the west side of the central stadium (the maximum flood depth reaches more than $0.3 \mathrm{~m}$ ), the intersection of Tingyun road and Heyuan West Road (the maximum flood depth is also above $0.3 \mathrm{~m}$ ), and near Qinchunyuan supermarket (the maximum flood depth reaches more than $0.2 \mathrm{~m}$ ). In addition, most of the maximum submergence depth in the study area is below $0.1 \mathrm{~m}$. The simulated submergence position and submergence depth are consistent with the actual inundation situation in the study area. Therefore, the model can be used to simulate and evaluate the operation of the drainage system in the study area.

The operation of drainage system with return periods $(2,5,10,20$ years $)$ was simulated by using the rainstorm intensity formula with stationary assumption as the input of the model. The inundation at RP 2 is similar to the observed rainstorm in 2017. With the increase of recurrence period, the location of the seriously affected area did not change significantly, but the depth and area of water accumulation increased significantly. In addition to several main ponding points, the ponding mainly occurred on the road. In the case of RP 20, the main roads in the study area were flooded to varying degrees. Compared with RP 2, the inundated flood volume of RP 5, RP 10 and RP 20 increased by 80\%, $138 \%$ and $190 \%$ respectively, and the maximum flood depth increased by $30 \%, 46 \%$ and $86 \%$ respectively. This is in accordance with the actual hydrological law and further illustrates the reliability of the 
model. (Fig. 9 and Table. 3)

Table. 3 Verification results: Stationarity assumes average floodwater statistics for RP 2, 5, 10, 20 and the flood event statistics on August 12, 2017

\begin{tabular}{ccccc}
\hline scenario & $\begin{array}{c}\text { Number of } \\
\text { flooded cells }\end{array}$ & Maximum flood & Average flood & Floodwater \\
\hline 20170812 & 7266 & 0.336 & 0.034 & volume $\left(\mathrm{m}^{3}\right)$ \\
RP 2 & 8437 & 0.336 & 0.033 & 7046.8 \\
RP 5 & 15949 & 0.439 & 0.041 & 12683.4 \\
RP 10 & 19723 & 0.490 & 0.048 & 16818.7 \\
RP 20 & 24635 & 0.626 & 0.051 & 20434.3 \\
\hline
\end{tabular}
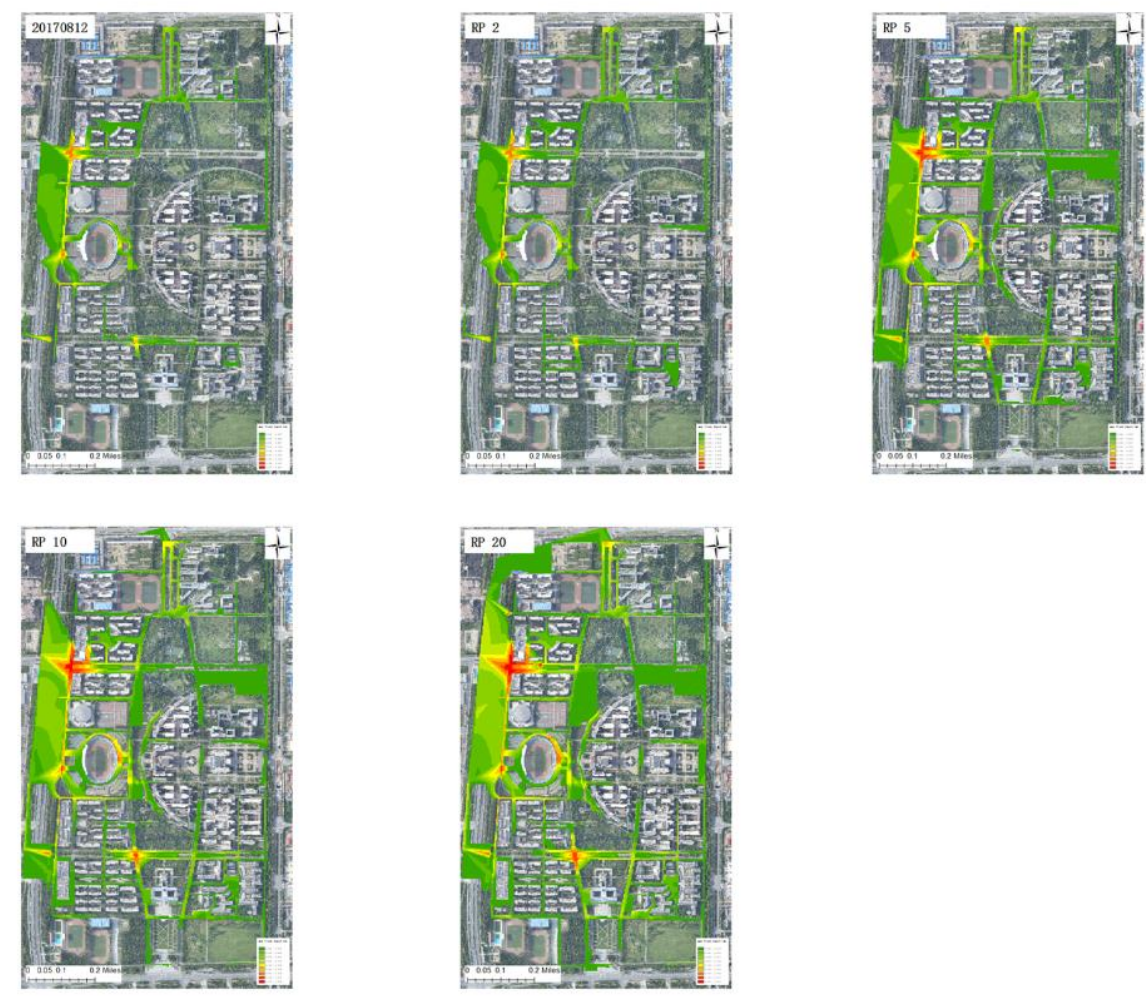

Fig. 9 Verification results: Stationarity assumes maximum floodwater depth 
maps for RP 2, 5, 10, 20 and the maximum floodwater depth map on August 12, 2017

\subsubsection{Impacts on simulation of urban drainage system}

The results of four return periods are simulated to determine the performance of rainstorm intensity formula in the environmental change of urban drainage system. There are obvious differences in flood range and depth in the whole study area (Fig. $\underline{10}$ and Table. 4). In terms of flood inundation area, although the serious inundation area did not change, the less serious area changed greatly and new areas were submerged. At RP 5, the difference ratio of submerged cells of (a), (b), (c) relative to (d) is $-24.5 \%, 18.5 \%$ and $24.6 \%$ respectively. At RP 2, this gap reaches the maximum. In terms of flood depth, the maximum flood depth of (d) is larger than that of (a), but it is obviously smaller than that of (b) and (c).

Table. 4 Average floodwater statistics for RP 2, 5, 10, 20 under three scenarios of non-stationarity assumption

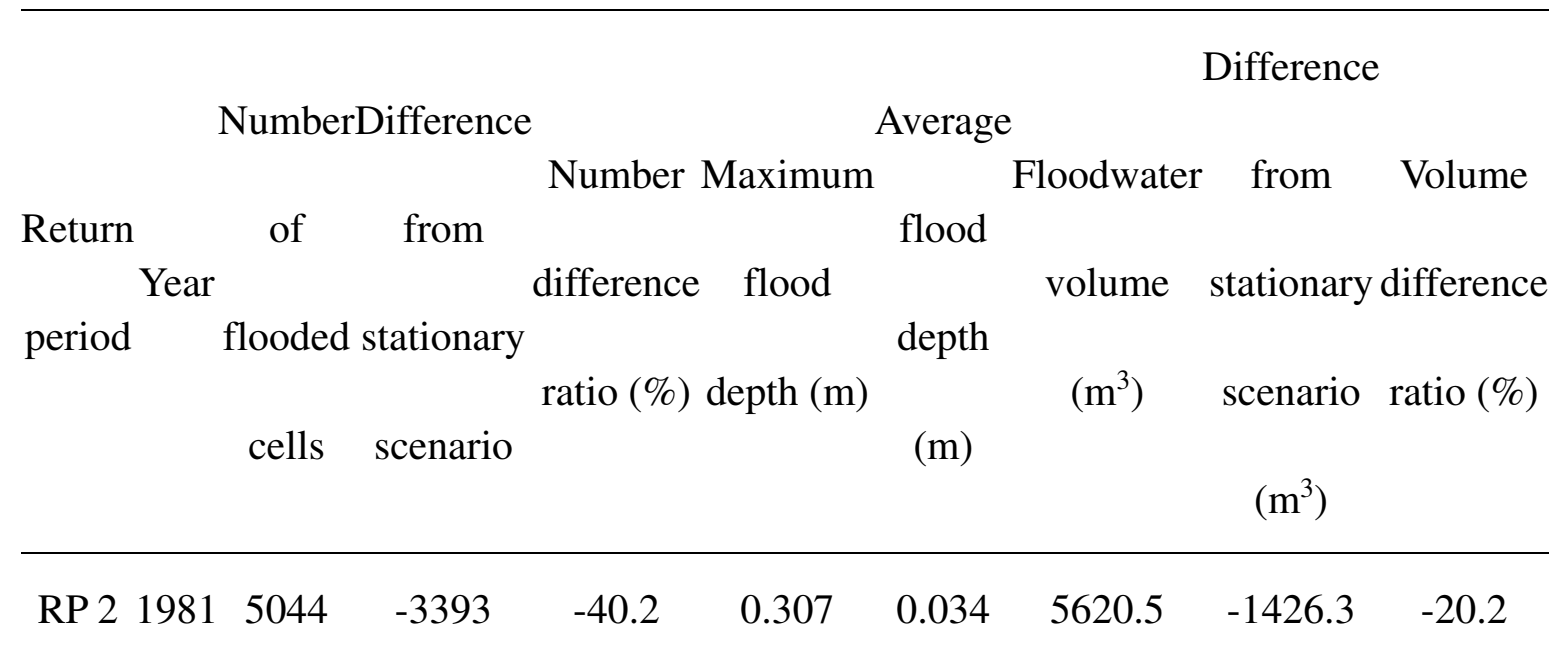




\begin{tabular}{|c|c|c|c|c|c|c|c|}
\hline 201014249 & 5812 & 68.9 & 0.406 & 0.036 & 10787.1 & 3740.3 & 53.1 \\
\hline 203015561 & 7124 & 84.4 & 0.434 & 0.039 & 12257.7 & 5210.9 & 73.9 \\
\hline 198112034 & -3915 & -24.5 & 0.431 & 0.044 & 11982.4 & -701.0 & -5.5 \\
\hline RP 5201018904 & 2955 & 18.5 & 0.477 & 0.045 & 15664.8 & 2981.4 & 23.5 \\
\hline 203019866 & 3917 & 24.6 & 0.494 & 0.048 & 16992.8 & 4309.4 & 34.0 \\
\hline 198117002 & -2712 & -13.8 & 0.489 & 0.048 & 16929.6 & 110.9 & 0.7 \\
\hline RP 10201023530 & 3807 & 19.3 & 0.513 & 0.047 & 19140.5 & 2321.8 & 13.8 \\
\hline 203024569 & 4846 & 24.6 & 0.527 & 0.050 & 20655.8 & 3837.1 & 22.8 \\
\hline 198120480 & -4155 & -16.9 & 0.531 & 0.055 & 21711.2 & 1276.9 & 6.2 \\
\hline RP 20201026799 & 2163 & 8.8 & 0.542 & 0.051 & 22756.7 & 2322.4 & 11.4 \\
\hline 203027303 & 2668 & 10.8 & 0.554 & 0.054 & 24219.7 & 3785.4 & 18.5 \\
\hline
\end{tabular}



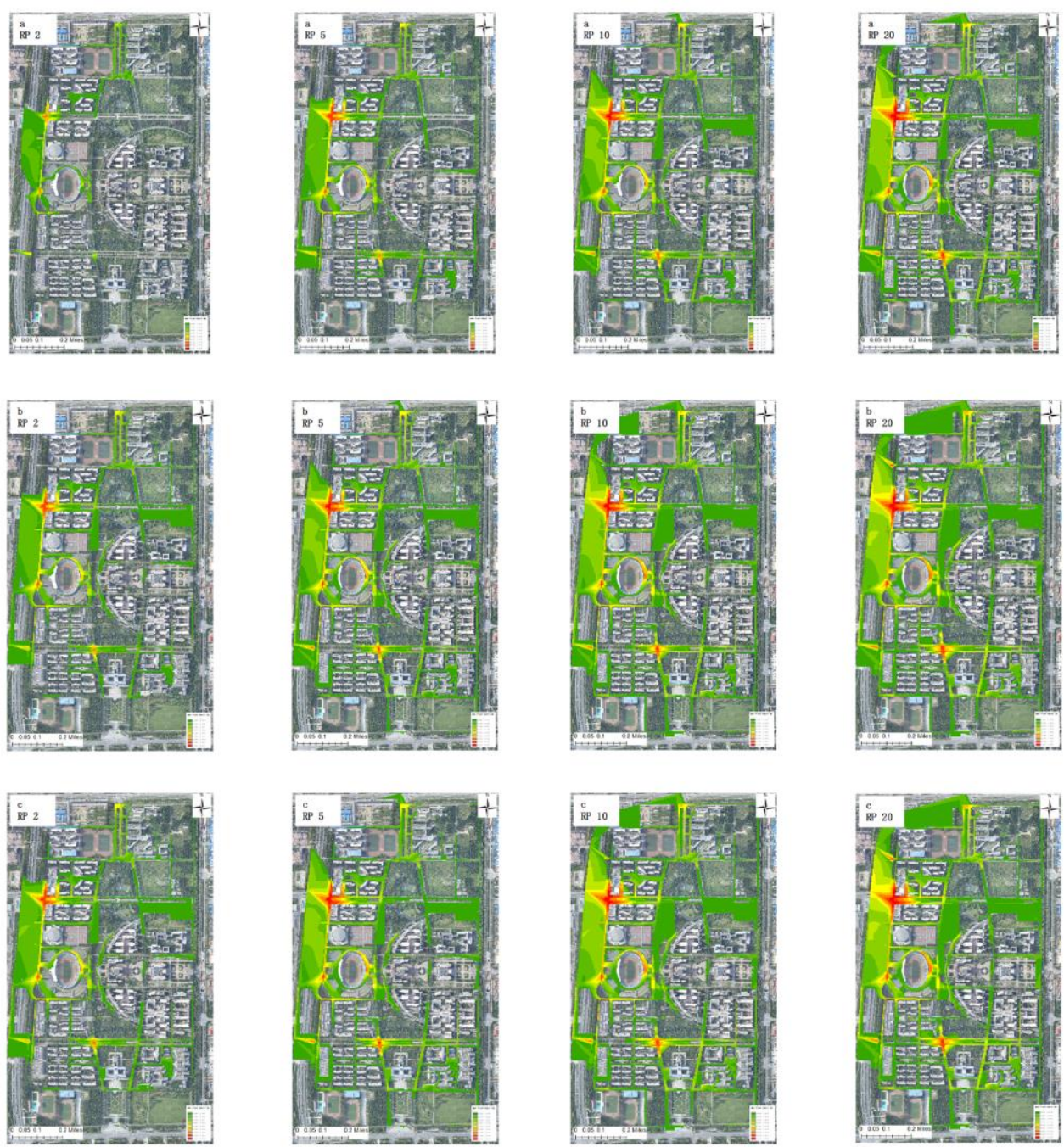

Fig. 10 Maximum floodwater depth maps for RP 2, 5, 10, 20 under three scenarios of non-stationarity assumption

In order to compare the difference of submergence depth in the same place under different scenarios, 160 cells were randomly selected as the samples of each scenario, and the maximum submergence depth of 160 cells in three scenarios was extracted. Scatter plots were drawn for the maximum flood depths of 160 sampling points in each return period (Fig. 11), where the $\mathrm{X}, \mathrm{Y}$, and $\mathrm{Z}$ axes represent the flood depths of the three cases (b), (c) and (d). In addition, the projection of sample points on three planes is also drawn. In all return periods, most of the points on the $\mathrm{X}-\mathrm{Z}$ and $\mathrm{Y}-\mathrm{Z}$ 
planes are below the 1:1 straight line, which indicates that the submergence depth of (b) and (c) is greater than that of (d) at the same location. On the X-Y plane, most of the points are located near the 1:1 straight line, but slightly higher than the straight line, which means that (c) the submergence depth at the same location is slightly greater than but close to (b). In addition, with the increase of return period, the sample points gradually approach the 1:1 straight line, which indicates that the difference of submergence depth between different scenarios gradually decreases with the increase of return period.

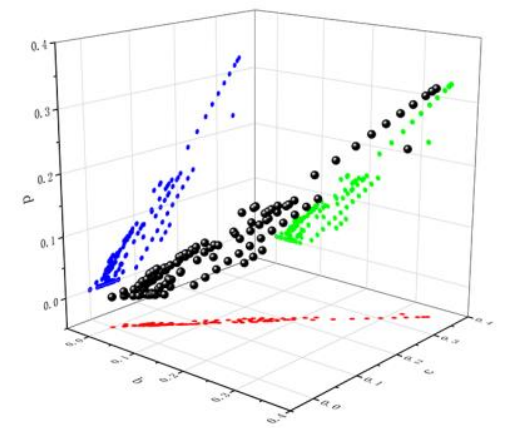

RP 2

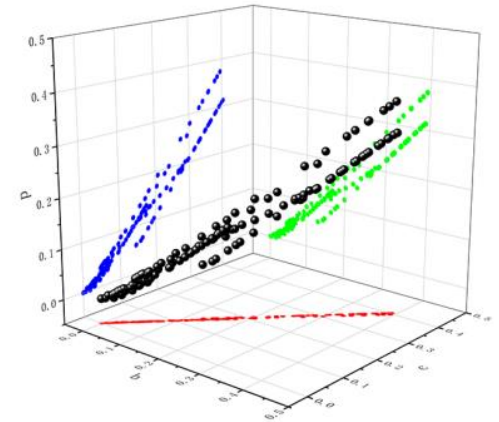

RP 10

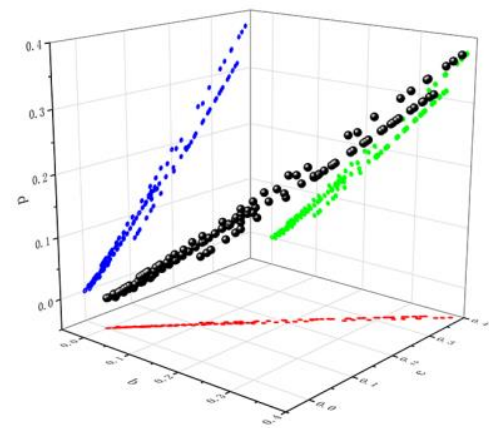

RP 5

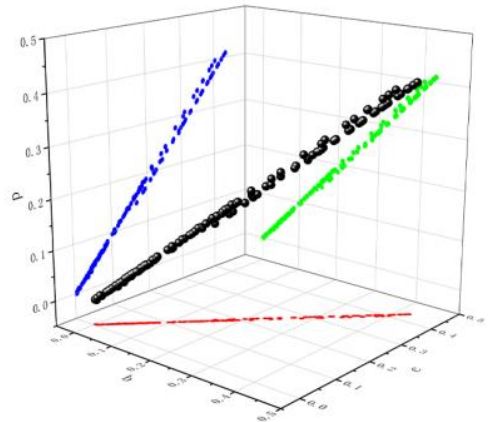

RP 20 unit: meter

Fig. 11 Comparison of maximum flood depth of three scenarios

In order to compare the overall difference of submergence depth in different scenarios, we calculated the flood depth of each unit and drew a violin diagram. From the violin diagram of flood depth in different return periods of four scenarios, it can 
be seen that the influence of rainstorm intensity formula in different scenarios on the unit flood depth is mainly reflected in the maximum flood depth and nuclear density, and the influence on the median is not obvious. In terms of the maximum flood depth, the maximum flood depth of (d) with two-year return period is greater than (a) and (b), close to (c), and (d) is the minimum in other periods. In terms of nuclear density, the violin diagram of (d) is "thinner", which means more uniform distribution. In addition, under the assumption of non-stationarity, the violin diagram is more "fat" over time, which means more concentrated distribution (Fig. 12).
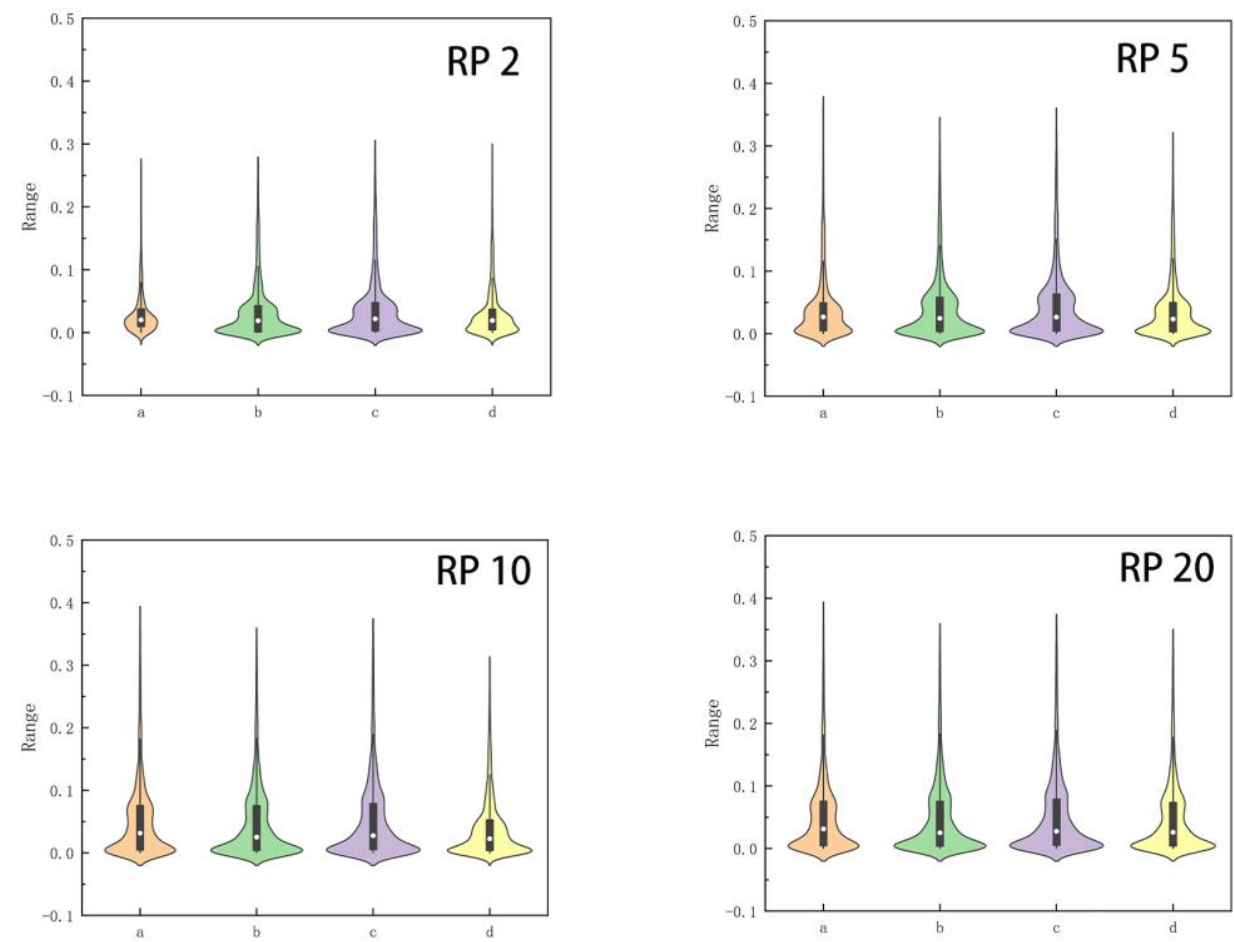

\section{Fig. 12 Comparison of maximum flood depth distribution in four scenarios}

In order to analyze the response of detailed water accumulation process of urban surface to different scenarios, the water accumulation process lines of two main water accumulation points (intersection of Tingyun road and Heyuan West Road, 
Qinchunyuan supermarket) were extracted. In the simulation process, these two water accumulation points are the two places most seriously affected. They are in the low-lying area and at the crossroads, with strong runoff generation capacity and low design standard of drainage network, so they are more vulnerable to flood damage. The flood hydrograph of (d) is much lower than that of (b) and (c) when the return period is five years. This means smaller flood depth and smaller flood volume. In addition, the time when the non-stationarity begins to submerge and the time when the flood depth reaches the peak is earlier than that of the stationary. This difference still exists once in 20 years, but it is not so significant. In the higher return period, the difference between different scenarios was not obvious (ig. 13).

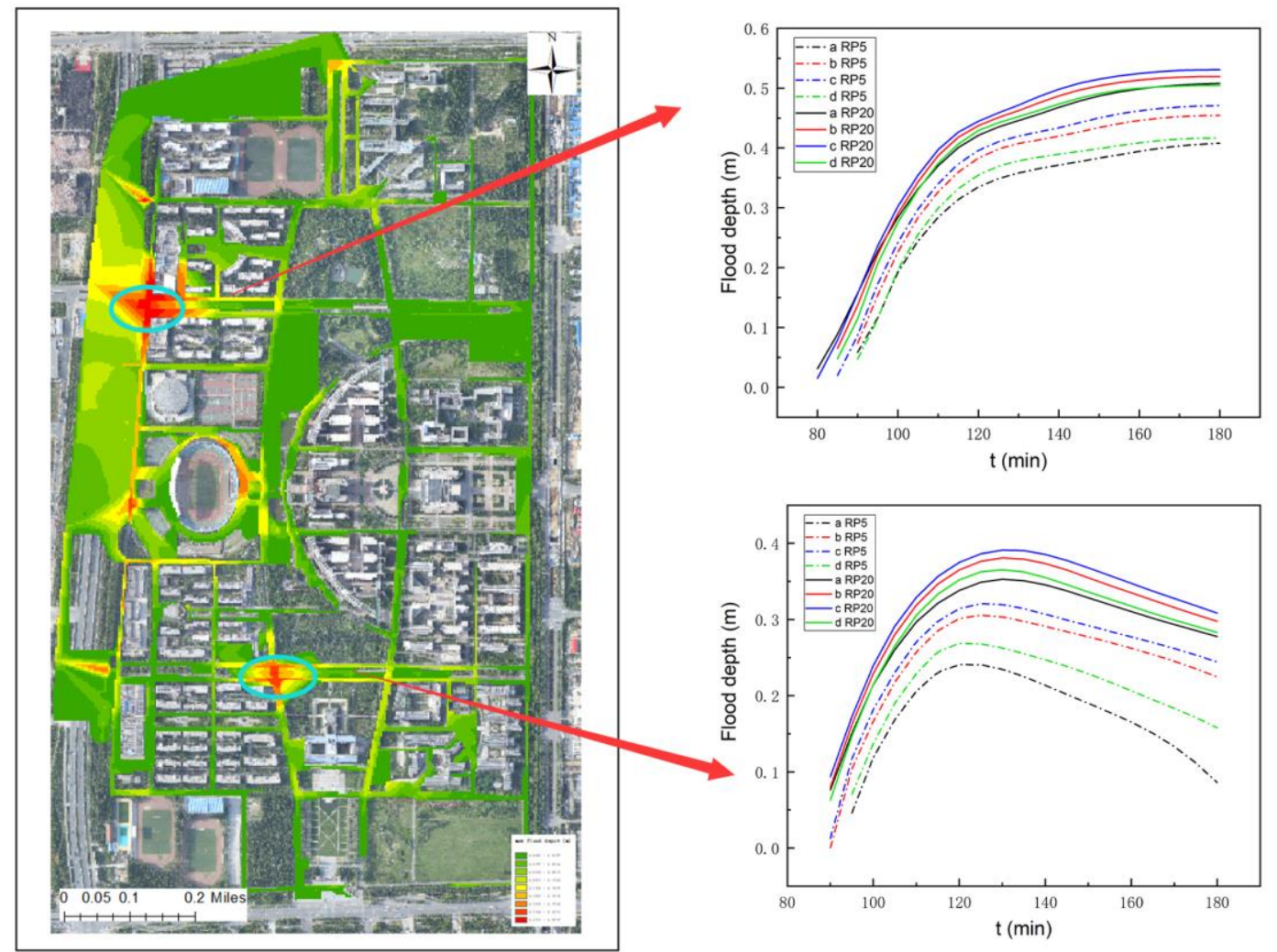

Fig. 13 Comparison of detailed water accumulation processes in four scenarios 


\section{Discussion}

Through the stationary test, it is found that the short duration Extreme Rainstorm Intensity Series in the study area may not conform to the stationary hypothesis. It showed an increasing trend, and there may be a mutation point in the significance level of 0.05 . Seven kinds of GAMLSS models are set up. From the view of model performance evaluation, the GAMLSS model with variable parameters has the best effect, which fully illustrates the non-stationary of the original sequence. According to the results of GAMLSS model, the rainstorm intensity formula based on stationary assumption does not consider the non-stationary caused by environmental changes, which is quite different from the rainstorm intensity formula based on non-stationary calculation. Although there is no specific rule for the parameters of short duration rainstorm intensity formula, some clues can be found in the design rainstorm. The design rainstorm based on non-stationary design has higher total precipitation, higher peak precipitation intensity and more concentrated precipitation process. Such design rainstorms pose a greater threat to the urban drainage system, and such design rainstorms with greater threat will be more serious in the future.

Four kinds of rainstorm intensity formulas are designed, which are based on the stationary assumption (d) and the non-stationary assumption of past (a), present (b) and future (c). Although the difference of rainstorm intensity formula of four scenarios in urban drainage system simulation decreases with the increase of rainstorm scale, this difference is still very important even in high return period. When the return period is 20 years, the flood volume of (b) is $11.4 \%$ more than that of 
(d), and the flood volume of (c) is $18.5 \%$ more than that of (d). The flooded area of (b) is $8.8 \%$ more than that of $(\mathrm{d})$, and the flooded area of (c) is $10.8 \%$ more than that (d). The difference can even reach more than $50 \%$ in the case of small scale rainstorm. The area that will not be submerged under the assumption of stationary may be submerged in the case of nonstationary. The non-stationary flood depth is higher than the stationary flood depth in the same place, and the flood depth in the future scenario is higher in the same place than the current situation. Although the flood depth at the same location has increased, the distribution of flood depth is more concentrated and mainly concentrated below the $25 \%$ quantile. This shows that the flood depth of the newly added flooded cells is mainly lower, and no new flood hot spots can be found from the map of maximum flood depth. Among the two flood hotspots extracted, the flood in Qinchunyuan supermarket has subsided, while the flood at the intersection of Tingyun road and Heyuan West Road is more and more serious. On the whole, the flood hydrograph of non-stationary scenario is higher than that of stationary scenario. However, the difference is also different in the two places, especially in the flood hot spot of Qinchunyuan, which is mainly reflected in the process of recession. From various perspectives, non-stationary scenarios provide more dangerous urban drainage simulation results, and this risk is more terrible in low return period and future environment.

In this paper, we only use time $\mathrm{t}$ as the explanatory variable to analyze the non-stationarity of extreme rainstorm. In fact, there are still many physical factors that can be used as explanatory variables and have achieved good results (Gao et al., 2018; 
Rashid and Beecham, 2019), such as North Pacific Oscillation (NPO), Pacific Decadal Oscillation(PDO), Arctic Oscillation (AO), El-Niño Southern Oscillation (ENSO), etc. In the future, more physical explanatory variables will be used to make up for the lack of using time as a covariate. In addition, we have established and verified the Mike Flood hydrodynamics model, but the model can not completely replace the real ponding process. The error between the simulation results and the actual results cannot be avoided and uncertainty analysis is needed. Soil properties and land cover are very important for urban flood while the underlying surface changes are not considered in this paper (Miller et al., 2014; Hossain et al., 2020). The impact of extreme rainstorm and underlying surface changes on urban drainage system may be comprehensively considered in the future.

\section{Conclusion}

The research results highlight the problems and challenges in the simulation of urban drainage system under the changing environment: the non-stationarity of extreme rainfall series makes the rainstorm intensity formula based on stationary assumption realize obvious deficiencies and risks in the simulation of urban drainage system, and this defect will be more important in the future. The characteristics of Extreme Rainstorm change rapidly, and the hydrological design standards are insufficient. How to deal with the low design standards caused by the non-stationarity of extreme rainfall series under changing environment is also an important challenge for urban flood control and disaster prevention. The urbanization and sustainable 
development of China and other countries in the world need to study the current and future rainstorm intensity formula and its impact on urban drainage system under changing conditions. Through GAMLSS model and Mike Flood The model discusses the influence of non-stationary short duration rainstorm intensity formula on urban drainage system, points out the risk of continuing to use the original scheme, and provides a non-stationary solution considering the changing environment for the local people. These works are important for the coordination of municipal drainage engineering design, alleviating the increasingly serious urban flood disaster, and strengthening the construction of urban waterlogging prevention and drainage system Make sense.

\section{Acknowledgements}

The authors thank the Zhengzhou University logistics office for providing Pipe network data and Zhengzhou Meteorological Bureau for rainfall data.

\section{Ethical Approval}

Not applicable

\section{Code availability}

Not applicable

\section{Consent to Participate}

Not applicable

\section{Consent to Publish}

Not applicable

\section{Authors Contributions}


All authors contributed to the study conception and design. Material preparation, data collection and analysis were performed by Z. Wu, S. Liu, H. Wang. This revision version of the manuscript was written by $\mathrm{S}$. Liu, and reviewed by $\mathrm{Z}$. Wu, H. Wang. All authors read and approved the final manuscript.

\section{Funding}

The study was funded by the Key Project of National Natural Science Foundation of China (No: 51739009); Natural Science Foundation of China (51879242); Science and Technology Innovation Talents Project of Henan Education Department of China (21HASTIT011); Young backbone Teachers Training Fund of Henan Education Department of China (2020GGJS005); Excellent Youth Fund of Henan Province of China (212300410088).

\section{Competing Interests}

None

\section{Availability of data and materials}

All data and materials may be obtained from the corresponding author upon reasonable request.

\section{References}

Abass, K., Buor, D., Afriyie, K., Dumedah, G., Segbefi, A. Y., Guodaar, L., . . Gyasi, R. M. (2020). Urban sprawl and green space depletion: Implications for flood incidence in Kumasi, Ghana. International Journal of Disaster Risk Reduction, 51, 101915. doi:https://doi.org/10.1016/j.ijdrr.2020.101915

Agilan, V., \& Umamahesh, N. V. (2016). Is the covariate based non-stationary rainfall IDF curve capable of encompassing future rainfall changes? Journal of 
Hydrology, 541, 1441-1455. doi:https://doi.org/10.1016/j.jhydrol.2016.08.052

Agilan, V., \& Umamahesh, N. V. (2017). Modelling nonlinear trend for developing non-stationary rainfall intensity-duration-frequency curve. International Journal of Climatology, 37(3), 1265-1281. doi:10.1002/joc.4774

Agilan, V., \& Umamahesh, N. V. (2017). Non-Stationary Rainfall Intensity-Duration-Frequency Relationship: a Comparison between Annual Maximum and Partial Duration Series. Water Resources Management, 31(6), 1825-1841. doi:10.1007/s11269-017-1614-9

Ahmad, I., Tang, D., Wang, T., Wang, M., \& Wagan, B. (2015). Precipitation Trends over Time Using Mann-Kendall and Spearman's rho Tests in Swat River Basin, Pakistan. Advances in Meteorology, 2015, 15. doi:10.1155/2015/431860

Andimuthu, R., Kandasamy, P., Mudgal, B. V., Jeganathan, A., Balu, A., \& Sankar, G. (2019). Performance of urban storm drainage network under changing climate scenarios: Flood mitigation in Indian coastal city. Scientific Reports, 9, 10. doi:10.1038/s41598-019-43859-3

Anker, Y., Mirlas, V., Gimburg, A., Zilberbrand, M., Nakonechny, F., Meir, I., \& Inbar, M. (2019). Effect of rapid urbanization on Mediterranean karstic mountainous drainage basins. Sustainable Cities and Society, 51, 101704. doi:https://doi.org/10.1016/j.scs.2019.101704

Arnbjerg-Nielsen, K., Willems, P., Olsson, J., Beecham, S., Pathirana, A., Gregersen, I. B., . . Nguyen, V. T. V. (2013). Impacts of climate change on rainfall extremes and urban drainage systems: a review. Water Science and Technology, 68(1), 16-28. doi:10.2166/wst.2013.251

Balistrocchi, M., \& Grossi, G. (2020). Predicting the impact of climate change on urban drainage systems in northwestern Italy by a copula-based approach. 
Journal of Hydrology: Regional Studies, 28, 100670. doi:https://doi.org/10.1016/j.ejrh.2020.100670

Banerjee, C., Sharma, A., \& D, N. K. (2020). Decline in terrestrial water recharge with increasing global temperatures. Science of The Total Environment, 142913. doi:https://doi.org/10.1016/j.scitotenv.2020.142913

Bertilsson, L., Wiklund, K., Tebaldi, I. D., Rezende, O. M., Verol, A. P., \& Miguez, M. G. (2019). Urban flood resilience - A multi-criteria index to integrate flood resilience into urban planning. Journal of Hydrology, 573, 970-982. doi:10.1016/j.jhydrol.2018.06.052

Chen, Y., Zhou, H., Zhang, H., Du, G., \& Zhou, J. (2015). Urban flood risk warning under rapid urbanization. Environmental Research, 139, 3-10. doi:https://doi.org/10.1016/j.envres.2015.02.028

Cheng, L. Y., \& AghaKouchak, A. (2014). Nonstationary Precipitation Intensity-Duration-Frequency Curves for Infrastructure Design in a Changing Climate. Scientific Reports, 4, 6. doi:10.1038/srep07093

Coulibaly, P., \& Baldwin, C. K. (2005). Nonstationary hydrological time series forecasting using nonlinear dynamic methods. Journal of Hydrology, 307(1-4), 164-174. doi:10.1016/j.jhydrol.2004.10.008

Danish Hydraulic Institute (DHI), 2017. Collection System. Modelling of storm water drainage networks and sewer collection systems. MIKE URBAN® user's guide, 2017.

Debele, S. E., Bogdanowicz, E., \& Strupczewski, W. G. (2017). Around and about an application of the GAMLSS package to non-stationary flood frequency analysis. Acta Geophysica, 65(4), 885-892. doi:10.1007/s11600-017-0072-3

Denault, C., Millar, R. G., \& Lence, B. J. (2006). Assessment of possible impacts of 
climate change in an urban catchment. Journal of the American Water Resources Association, 42(3), 685-697. doi:10.1111/j.1752-1688.2006.tb04485.x

Douglas, I., Alam, K., Maghenda, M., McDonnell, Y., McLean, L., \& Campbell, J. (2008). Unjust waters: climate change, flooding and the urban poor in Africa. Environment and Urbanization, 20(1), 187-205. doi:10.1177/0956247808089156

Edenhofer, O., \& Seyboth, K. (2013). Intergovernmental Panel on Climate Change (IPCC). In J. F. Shogren (Ed.), Encyclopedia of Energy, Natural Resource, and Environmental Economics (pp. 48-56). Waltham: Elsevier.

Forzieri, G., Bianchi, A., Silva, F. B. E., Marin Herrera, M. A., Leblois, A., Lavalle, C., . . Feyen, L. (2018). Escalating impacts of climate extremes on critical infrastructures in Europe. Global Environmental Change, 48, 97-107. doi:10.1016/j.gloenvcha.2017.11.007

Fujibe, F. (2013). Clausius-Clapeyron-like relationship in multidecadal changes of extreme short-term precipitation and temperature in Japan. Atmospheric Science Letters, 14(3), 127-132. doi:10.1002/as12.428

Gao, L., Huang, J., Chen, X. W., Chen, Y., \& Liu, M. B. (2018). Contributions of natural climate changes and human activities to the trend of extreme precipitation. Atmospheric Research, 205, 60-69. doi:10.1016/j.atmosres.2018.02.006

Hao, W. L., Shao, Q. X., Hao, Z. C., Ju, Q., Baima, W., \& Zhang, D. W. (2019). Non-stationary modelling of extreme precipitation by climate indices during rainy season in Hanjiang River Basin, China. International Journal of Climatology, 39(10), 4154-4169. doi:10.1002/joc.6065

Hossain Anni, A., Cohen, S., \& Praskievicz, S. (2020). Sensitivity of urban flood simulations to stormwater infrastructure and soil infiltration. Journal of 
Hydrology, 588, 125028. doi:https://doi.org/10.1016/j.jhydrol.2020.125028

Hosseinzadehtalaei, P., Tabari, H., \& Willems, P. (2020). Climate change impact on short-duration extreme precipitation and intensity-duration-frequency curves $\begin{array}{lllll}\text { over Europe. Journal of Hydrology, 590, } 125249 . & \end{array}$ doi:https://doi.org/10.1016/j.jhydrol.2020.125249

Huong, H. T. L., \& Pathirana, A. (2013). Urbanization and climate change impacts on future urban flooding in Can Tho city, Vietnam. Hydrology and Earth System Sciences, 17(1), 379-394. doi:10.5194/hess-17-379-2013

Khaliq, M. N., Ouarda, T. B. M. J., Ondo, J. C., Gachon, P., \& Bobée, B. (2006). Frequency analysis of a sequence of dependent and/or non-stationary hydro-meteorological observations: A review. Journal of Hydrology, 329(3), 534-552. doi:https://doi.org/10.1016/j.jhydrol.2006.03.004

Kundzewicz, Z. W., Kanae, S., Seneviratne, S. I., Handmer, J., Nicholls, N., Peduzzi, P., . . Sherstyukov, B. (2014). Flood risk and climate change: global and regional perspectives. Hydrological Sciences Journal-Journal Des Sciences Hydrologiques, 59(1), 1-28. doi:10.1080/02626667.2013.857411

Li, J., \& Tan, S. (2015). Nonstationary Flood Frequency Analysis for Annual Flood Peak Series, Adopting Climate Indices and Check Dam Index as Covariates. Water Resources $\quad$ Management, 29(15), 5533-5550. doi:10.1007/s11269-015-1133-5

Li, H., Zhou, Y., Wang, X., Zhou, X., Zhang, H., \& Sodoudi, S. (2019). Quantifying urban heat island intensity and its physical mechanism using WRF/UCM. Science of The Total Environment, 650, 3110-3119. doi:https://doi.org/10.1016/j.scitotenv.2018.10.025

Lima, C. H. R., Kwon, H.-H., \& Kim, J.-Y. (2016). A Bayesian beta distribution 
model for estimating rainfall IDF curves in a changing climate. Journal of Hydrology, 540, 744-756. doi:https://doi.org/10.1016/j.jhydrol.2016.06.062

Lima, C. H. R., Kwon, H.-H., \& Kim, Y.-T. (2018). A local-regional scaling-invariant Bayesian GEV model for estimating rainfall IDF curves in a future climate. $\begin{array}{llll}\text { Journal of } & \text { Hydrology, } & 566, & 73-88 .\end{array}$ doi:https://doi.org/10.1016/j.jhydrol.2018.08.075

Liu, J., \& Niyogi, D. (2020). Identification of linkages between urban heat Island magnitude and urban rainfall modification by use of causal discovery algorithms. Urban Climate, 33, 100659. doi:https://doi.org/10.1016/j.uclim.2020.100659

Machado, M. J., Botero, B. A., Lopez, J., Frances, F., Diez-Herrero, A., \& Benito, G. (2015). Flood frequency analysis of historical flood data under stationary and non-stationary modelling. Hydrology and Earth System Sciences, 19(6), 2561-2576. doi:10.5194/hess-19-2561-2015

Madsen, H., Arnbjerg-Nielsen, K., \& Mikkelsen, P. S. (2009). Update of regional intensity-duration-frequency curves in Denmark: Tendency towards increased storm intensities. Atmospheric Research, 92(3), 343-349. doi:https://doi.org/10.1016/j.atmosres.2009.01.013

Miller, J. D., Kim, H., Kjeldsen, T. R., Packman, J., Grebby, S., \& Dearden, R. (2014). Assessing the impact of urbanization on storm runoff in a pen-urban catchment using historical change in impervious cover. Journal of Hydrology, 515, 59-70. doi:10.1016/j.jhydrol.2014.04.011

Milly, P. C. D., Betancourt, J., Falkenmark, M., Hirsch, R. M., Kundzewicz, Z. W., Lettenmaier, D. P., \& Stouffer, R. J. (2008). Climate change: Stationarity is dead: Whither water management? Science, 319(5863), 573-574. doi:10.1126/science.1151915 
Mishra, V., Ganguly, A. R., Nijssen, B., \& Lettenmaier, D. P. (2015). Changes in observed climate extremes in global urban areas. Environmental Research Letters, 10(2), 10. doi:10.1088/1748-9326/10/2/024005

Pour, S. H., Wahab, A. K. A., Shahid, S., Asaduzzaman, M., \& Dewan, A. (2020). Low impact development techniques to mitigate the impacts of climate-change-induced urban floods: Current trends, issues and challenges. $\begin{array}{lllll}\text { Sustainable } \quad \text { Cities } & \text { and }\end{array}$ doi:https://doi.org/10.1016/j.scs.2020.102373

Rahman, M. A., Lou, Y. S., \& Sultana, N. (2017). Analysis and prediction of rainfall trends over Bangladesh using Mann-Kendall, Spearman's rho tests and ARIMA model. Meteorology and Atmospheric Physics, 129(4), 409-424. doi:10.1007/s00703-016-0479-4

Rashid, M. M., \& Beecham, S. (2019). Development of a non-stationary Standardized Precipitation Index and its application to a South Australian climate. Science of $\begin{array}{lll}\text { The Total } & \text { Environment, } & \text { 857, }\end{array}$ doi:https://doi.org/10.1016/j.scitotenv.2018.12.052

Rigby, R. A., \& Stasinopoulos, D. M. (2005). Generalized additive models for location, scale and shape. Journal of the Royal Statistical Society Series C-Applied Statistics, 54, 507-544. doi:10.1111/j.1467-9876.2005.00510.x

Rosenberg, E. A., Keys, P. W., Booth, D. B., Hartley, D., Burkey, J., Steinemann, A. C., \& Lettenmaier, D. P. (2010). Precipitation extremes and the impacts of climate change on stormwater infrastructure in Washington State. Climatic Change, 102(1-2), 319-349. doi:10.1007/s10584-010-9847-0

Salas, J. D., \& Obeysekera, J. (2014). Revisiting the Concepts of Return Period and Risk for Nonstationary Hydrologic Extreme Events. Journal of Hydrologic 
Engineering, 19(3), 554-568. doi:10.1061/(asce)he.1943-5584.0000820

Salles, R., Belloze, K., Porto, F., Gonzalez, P. H., \& Ogasawara, E. (2019). Nonstationary time series transformation methods: An experimental review. $\begin{array}{lll}\text { Knowledge-Based } & \text { Systems, } & \text { 274-291. }\end{array}$ doi:https://doi.org/10.1016/j.knosys.2018.10.041

Stasinopoulos, D. M., \& Rigby, R. A. (2007). Generalized additive models for location scale and shape (GAMLSS) in R. Journal of Statistical Software, 23(7), 46.

Strupczewski, W. G., Singh, V. P., \& Feluch, W. (2001). Non-stationary approach to at-site flood frequency modelling I. Maximum likelihood estimation. Journal of Hydrology, 248(1), 123-142. doi:https://doi.org/10.1016/S0022-1694(01)00397-3

Villarini, G., \& Serinaldi, F. (2012). Development of statistical models for at-site probabilistic seasonal rainfall forecast. International Journal of Climatology, 32(14), 2197-2212. doi:10.1002/joc.3393

Villarini, G., Smith, J. A., Serinaldi, F., Bales, J., Bates, P. D., \& Krajewski, W. F. (2009). Flood frequency analysis for nonstationary annual peak records in an urban drainage basin. Advances in Water Resources, 32(8), 1255-1266. doi:10.1016/j.advwatres.2009.05.003

Wang, X., Jiang, D., \& Lang, X. (2017). Future extreme climate changes linked to global warming intensity. Science Bulletin, 62(24), 1673-1680. doi:https://doi.org/10.1016/j.scib.2017.11.004

Willems, P., Arnbjerg-Nielsen, K., Olsson, J., \& Nguyen, V. T. V. (2012). Climate change impact assessment on urban rainfall extremes and urban drainage: Methods and shortcomings. Atmospheric Research, 103, 106-118. doi:https://doi.org/10.1016/j.atmosres.2011.04.003 
Xiong, L., Yan, L., Du, T., Yan, P., Li, L., \& Xu, W. (2019). Impacts of Climate Change on Urban Extreme Rainfall and Drainage Infrastructure Performance: A Case Study in Wuhan City, China. Irrigation and Drainage, 68(2), 152-164. doi:10.1002/ird.2316

Yaduvanshi, A., Nkemelang, T., Bendapudi, R., \& New, M. (2020). Temperature and rainfall extremes change under current, $1.5^{\circ} \mathrm{C}, 2.0^{\circ} \mathrm{C}$ and $3.0^{\circ} \mathrm{C}$ global warming across Indian climate zones. Weather and Climate Extremes, 100291. doi:https://doi.org/10.1016/j.wace.2020.100291

Yang, L., Li, J., Kang, A., Li, S., \& Feng, P. (2020). The Effect of Nonstationarity in Rainfall on Urban Flooding Based on Coupling SWMM and MIKE21. Water Resources Management, 34(4), 1535-1551. doi:10.1007/s11269-020-02522-7

Yurekli, K. (2020). Scrutinizing variability in full and partial rainfall time series by different approaches. Natural Hazards. doi:10.1007/s11069-020-04410-0

Zhang, S., Zhang, J., Yue, T., \& Jing, X. (2019). Impacts of climate change on urban rainwater harvesting systems. Sci Total Environ, 665, 262-274. doi:10.1016/j.scitotenv.2019.02.135

Zhang, T., Wang, Y., Wang, B., Tan, S., \& Feng, P. (2018). Nonstationary Flood Frequency Analysis Using Univariate and Bivariate Time-Varying Models Based on GAMLSS. Water, 10(7). doi:10.3390/w10070819

Zheng, Z., Gao, J., Ma, Z., Wang, Z., Yang, X., Luo, X., . . . Fu, G. (2016). Urban flooding in China: main causes and policy recommendations. Hydrological Processes, 30(7), 1149-1152. doi:10.1002/hyp.10717

Zhou, X., Bai, Z., \& Yang, Y. (2017). Linking trends in urban extreme rainfall to urban flooding in China. International Journal of Climatology, 37(13), 4586-4593. doi:10.1002/joc.5107 
Figures
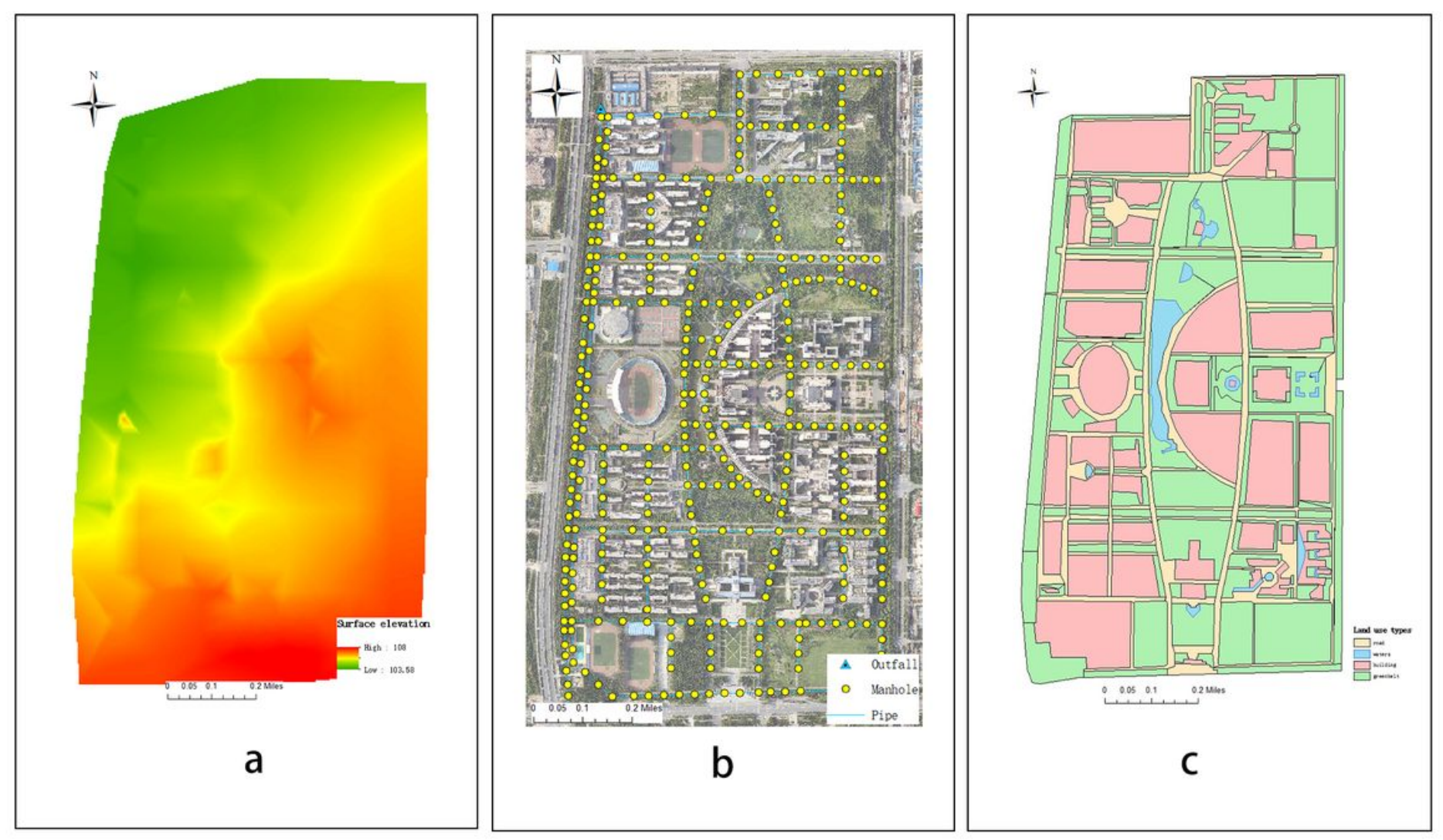

Figure 1

(a) DEM of the study site; (b) drainage system of the study site; (c) land use types 


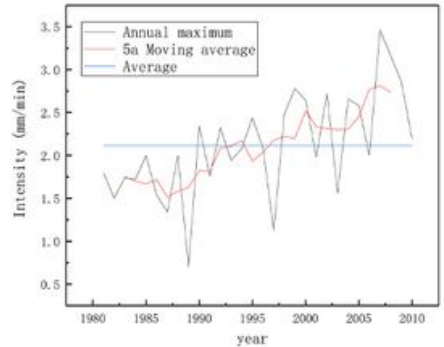

a
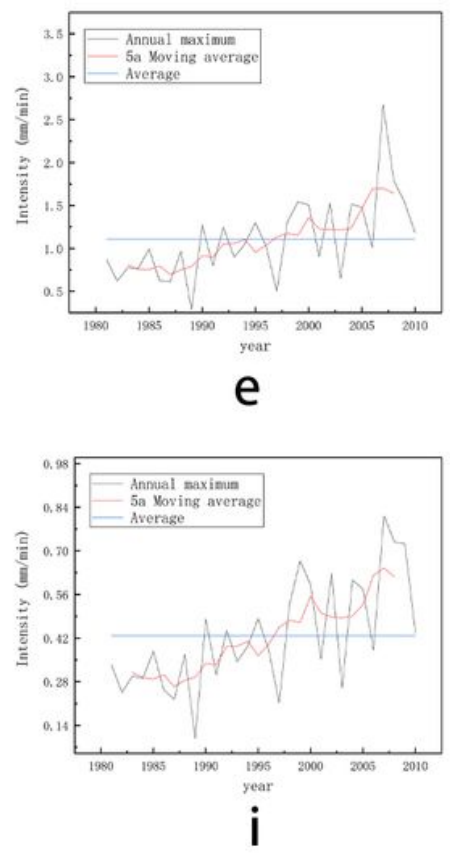

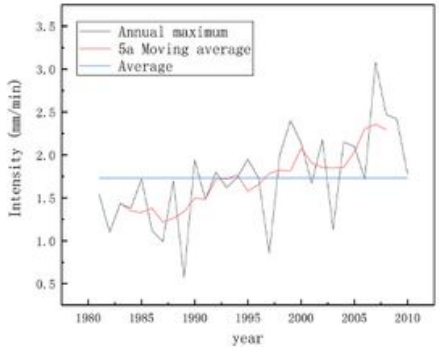

b
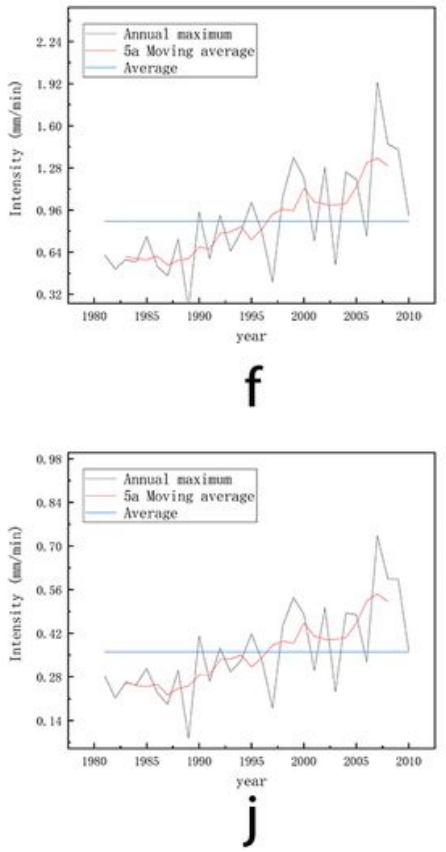

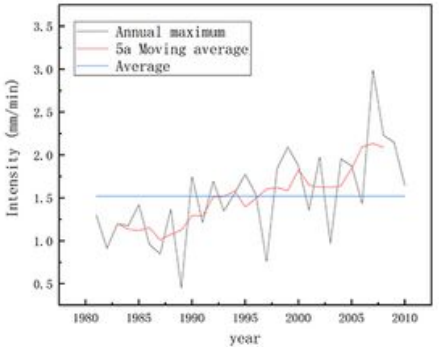

C
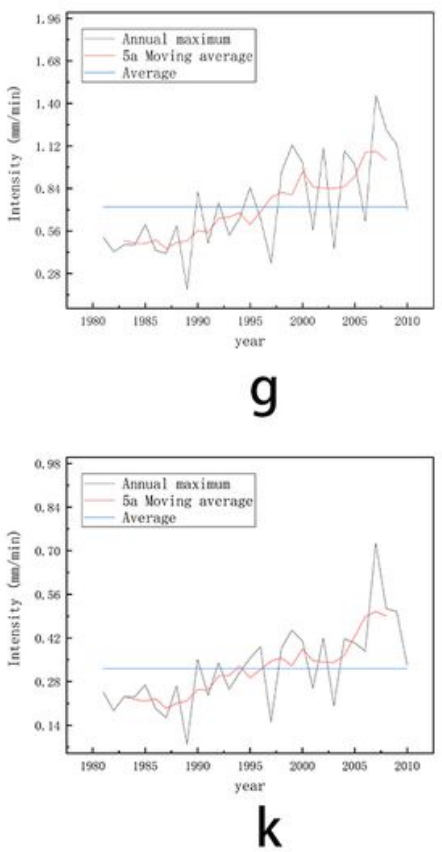

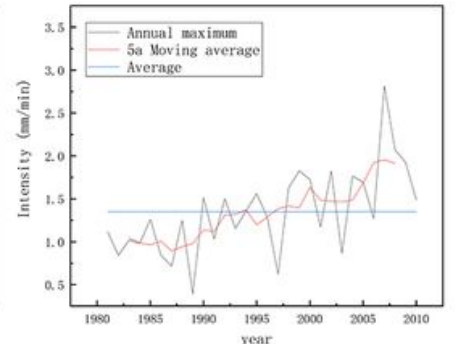

d

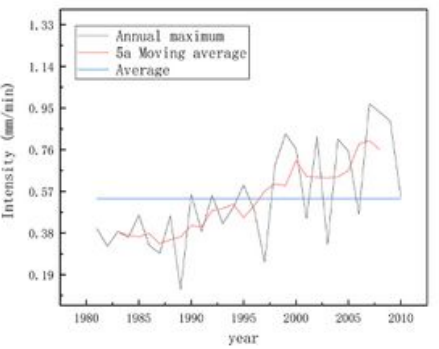

$\mathrm{h}$

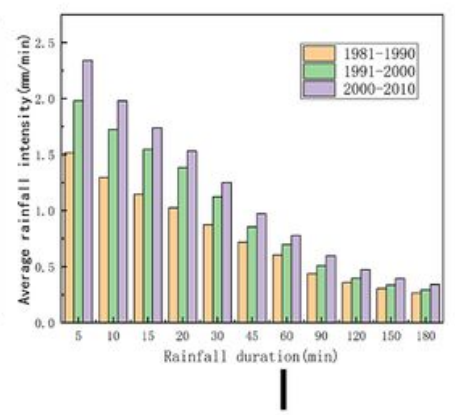

Figure 2

$(a-k)$ show the sequence value of annual maximum rainfall intensity and five-year moving average value of rainfall duration from 5 - 180 min. (l)is the bar chart of ten-year average value of maximum rainfall intensity in different rainfall periods 

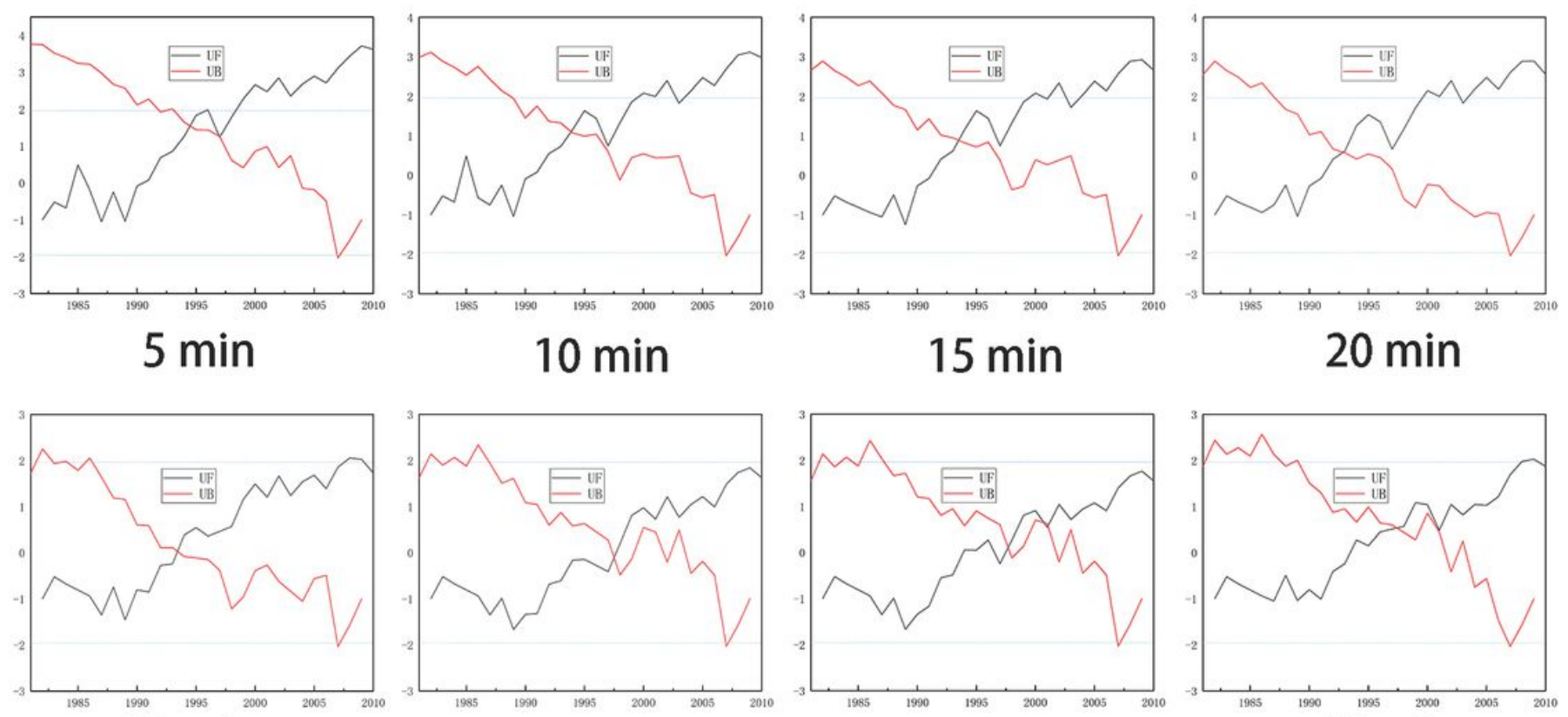

$30 \mathrm{~min}$

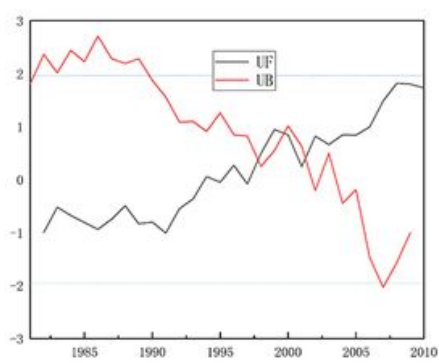

$120 \mathrm{~min}$

$45 \mathrm{~min}$

$60 \mathrm{~min}$

$90 \mathrm{~min}$

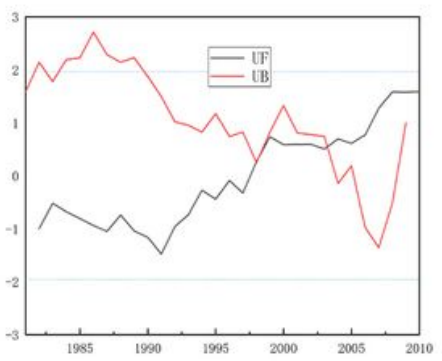

$150 \mathrm{~min}$

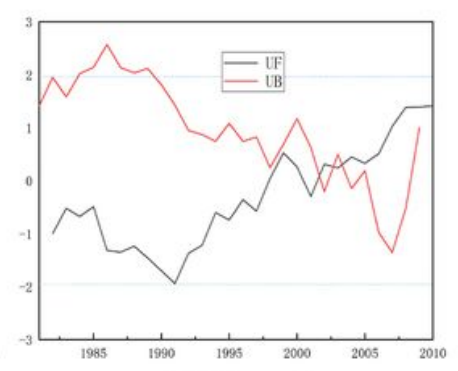

$180 \mathrm{~min}$

Figure 3

Mann - Kendall test results of annual maximum rainfall intensity series for each rainfall duration. (significance level is 0.05) 


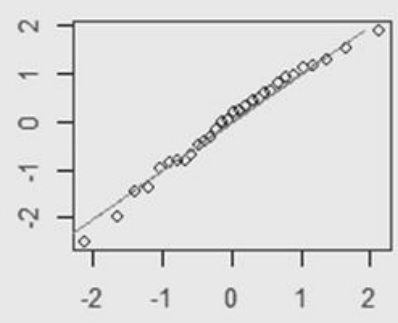

$5 \mathrm{~min}$

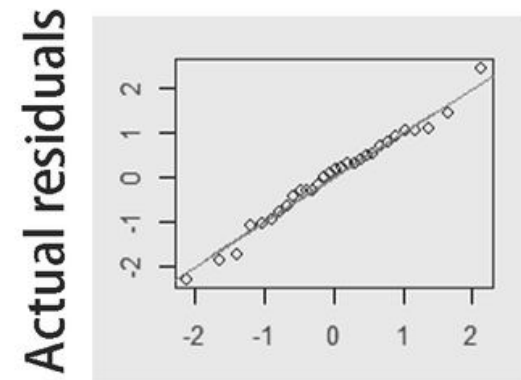

$30 \mathrm{~min}$

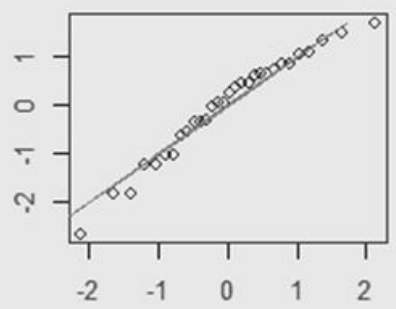

$120 \mathrm{~min}$

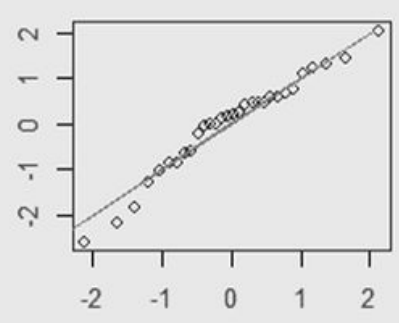

$10 \mathrm{~min}$

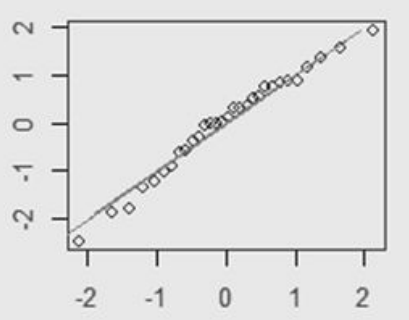

$45 \mathrm{~min}$

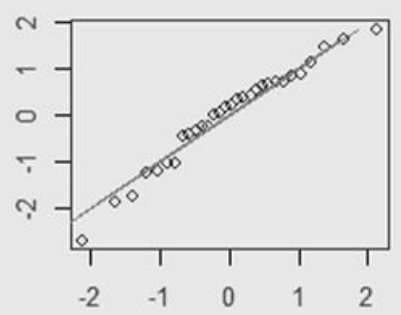

$150 \mathrm{~min}$

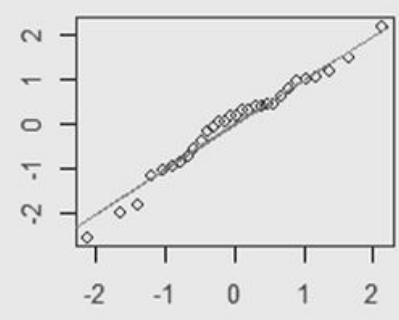

$15 \mathrm{~min}$

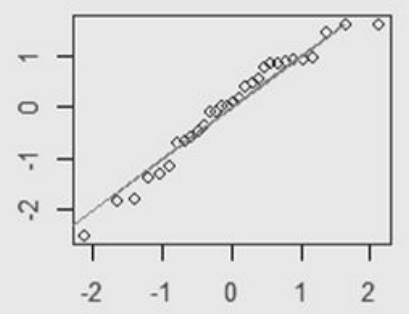

$60 \mathrm{~min}$

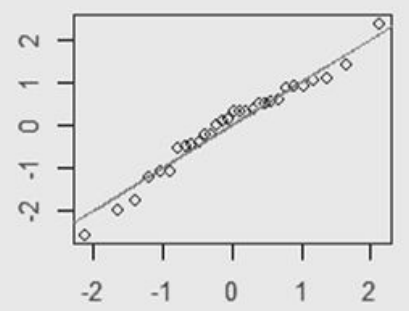

$180 \mathrm{~min}$

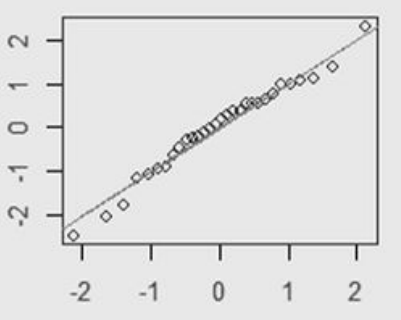

$20 \mathrm{~min}$

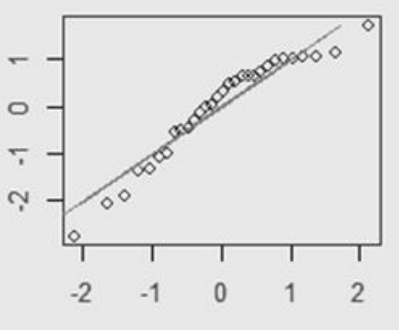

$90 \mathrm{~min}$

\section{Theoretical residuals}

\section{Figure 4}

Standard normal QQ chart based on selected GAMLSS model regression analysis 

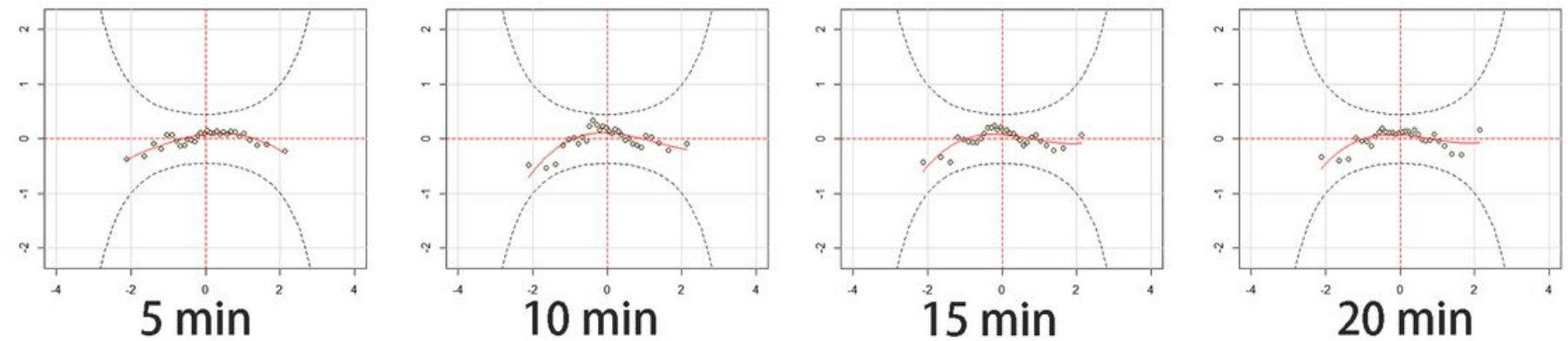
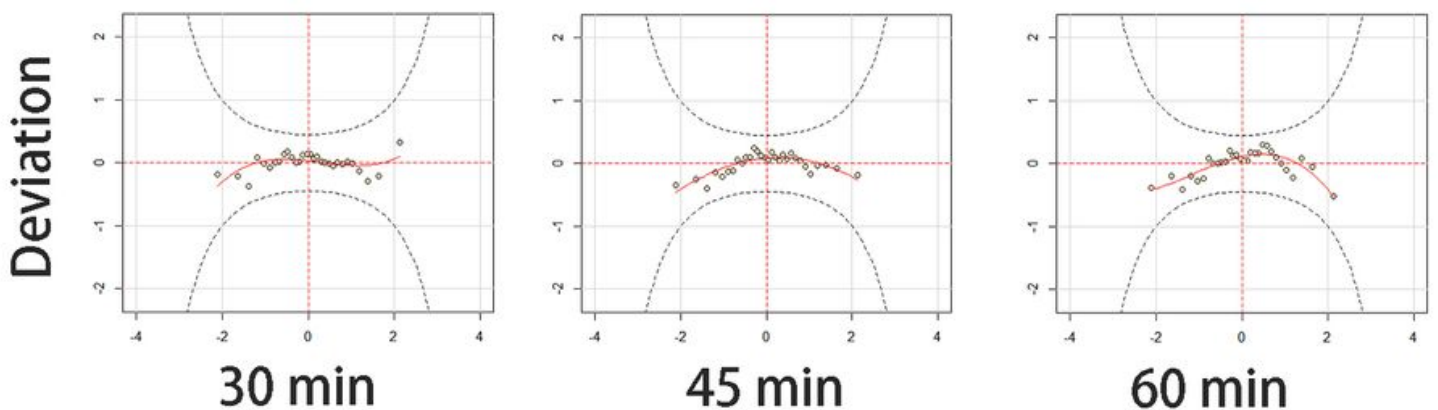

$60 \mathrm{~min}$

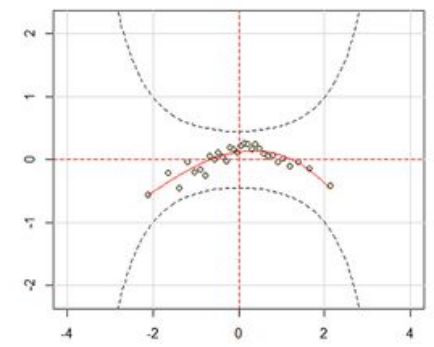

$120 \mathrm{~min}$

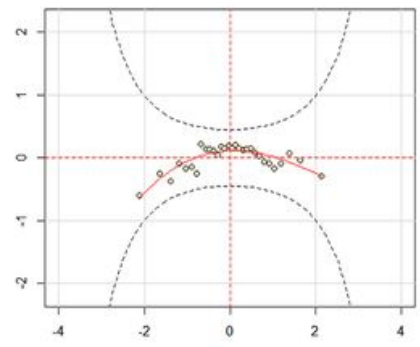

$150 \mathrm{~min}$

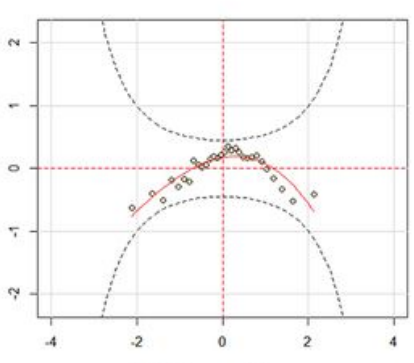

$90 \mathrm{~min}$

Unit normal quantile

Figure 5

Residual normal worm chart based on regression analysis of selected GAMLSS model 


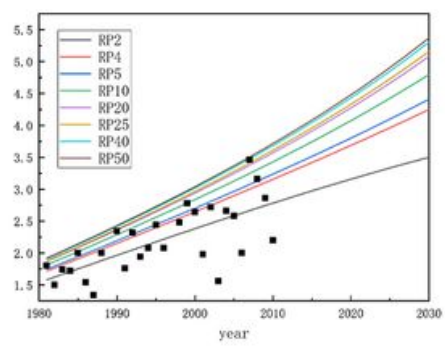

$5 \min$

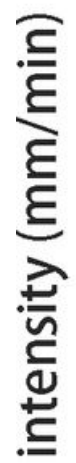

है

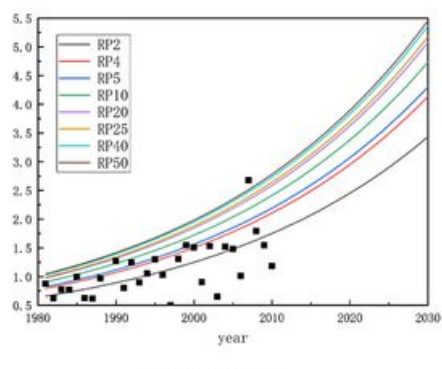

$30 \mathrm{~min}$

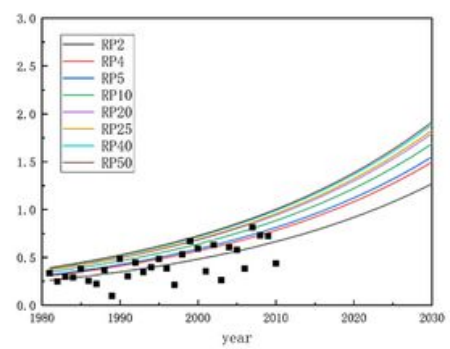

$120 \min$

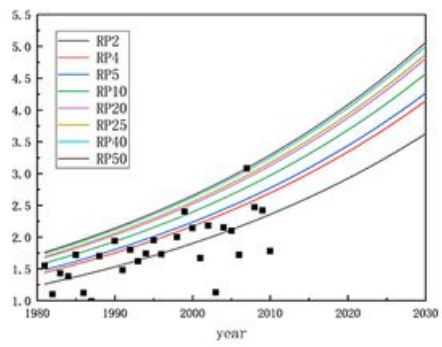

$10 \mathrm{~min}$

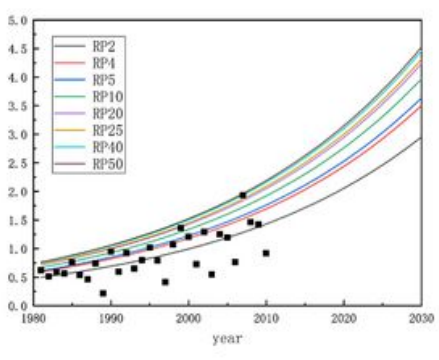

$45 \min$

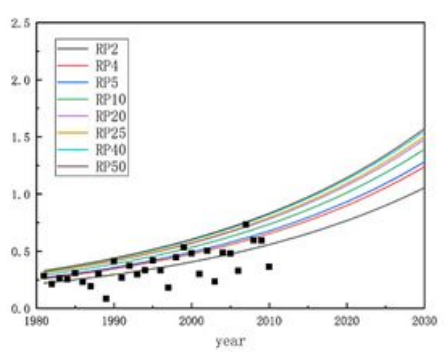

$150 \mathrm{~min}$

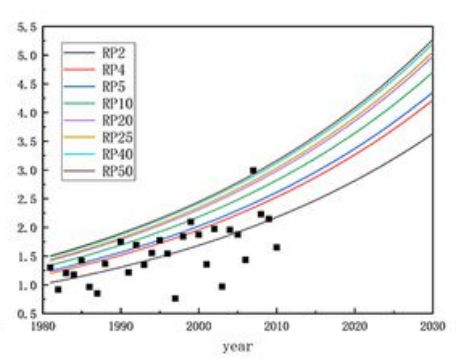

$15 \min$

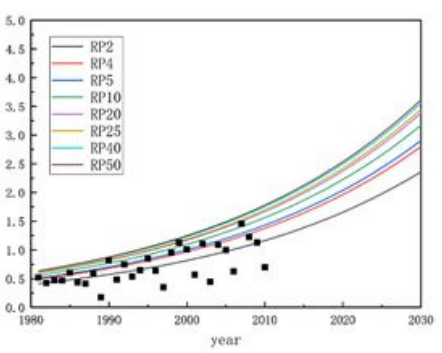

$60 \min$

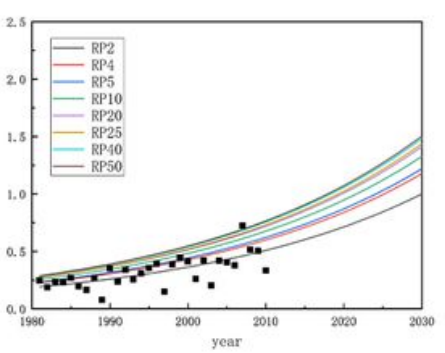

$180 \mathrm{~min}$

Figure 6

Design value curves of annual maximum rainfall intensity based on selected GAMLSS model 

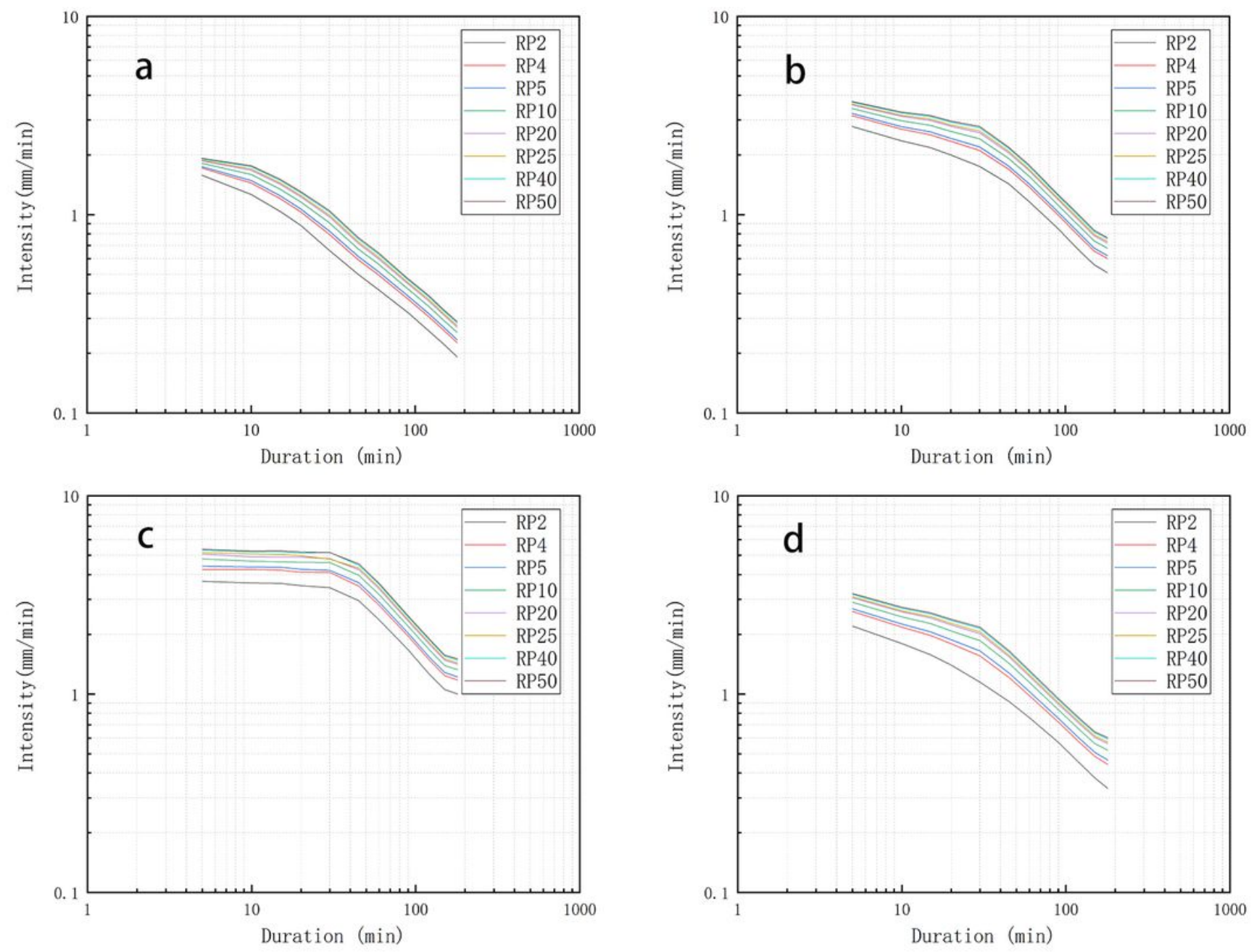

Figure 7

IDF curves under different scenarios; a (non-stationary past level - 1981); $b$ (non-stationary current level 2010); c (non-stationary future level - 2030); d (stationary hypothesis IDF curves) 

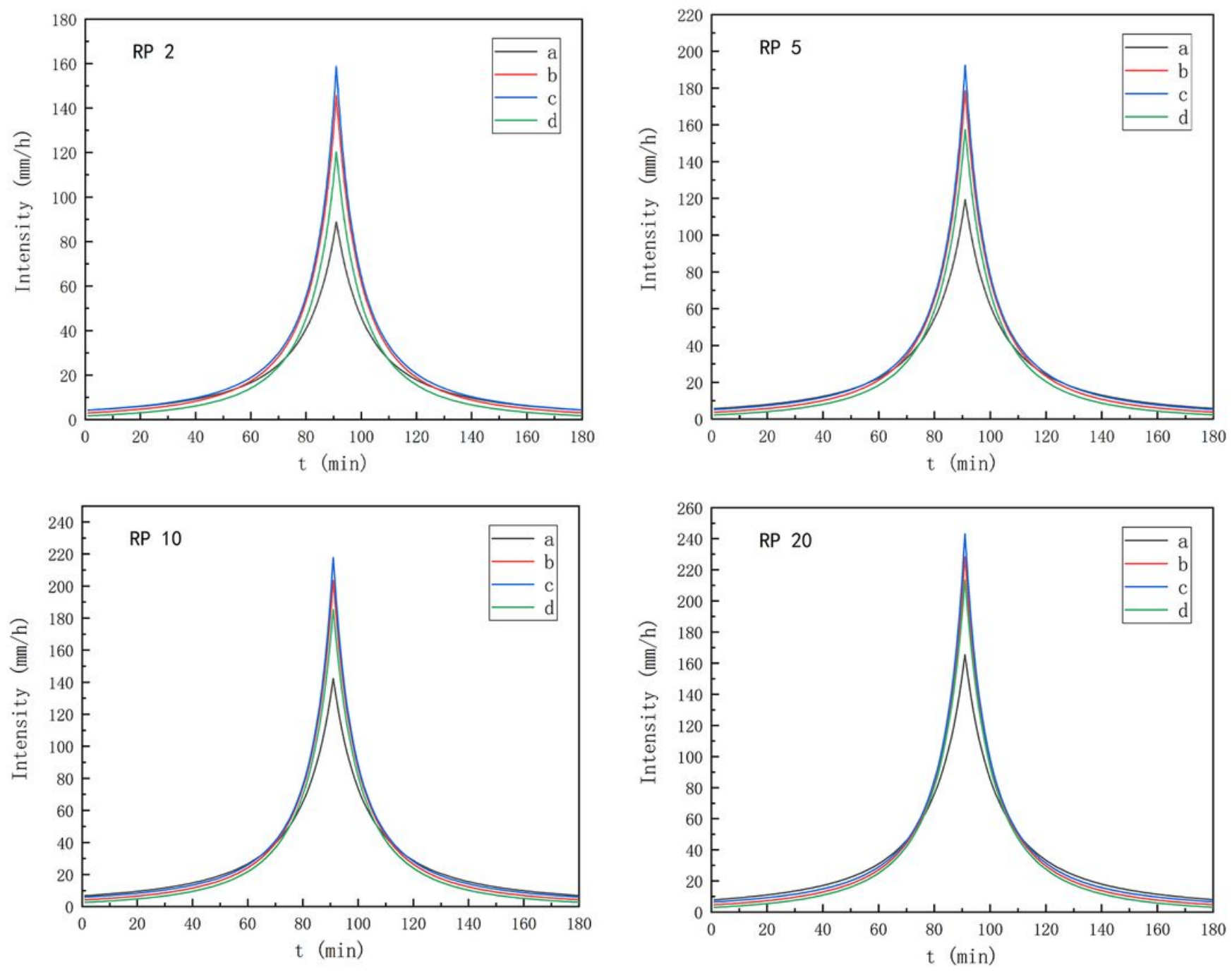

Figure 8

Design rainstorm processes of the four scenarios; a (non-stationary past level - 1981); b (non-stationary current level - 2010); c (non-stationary future level - 2030); d (stationary hypothesis design rainstorm processes) 

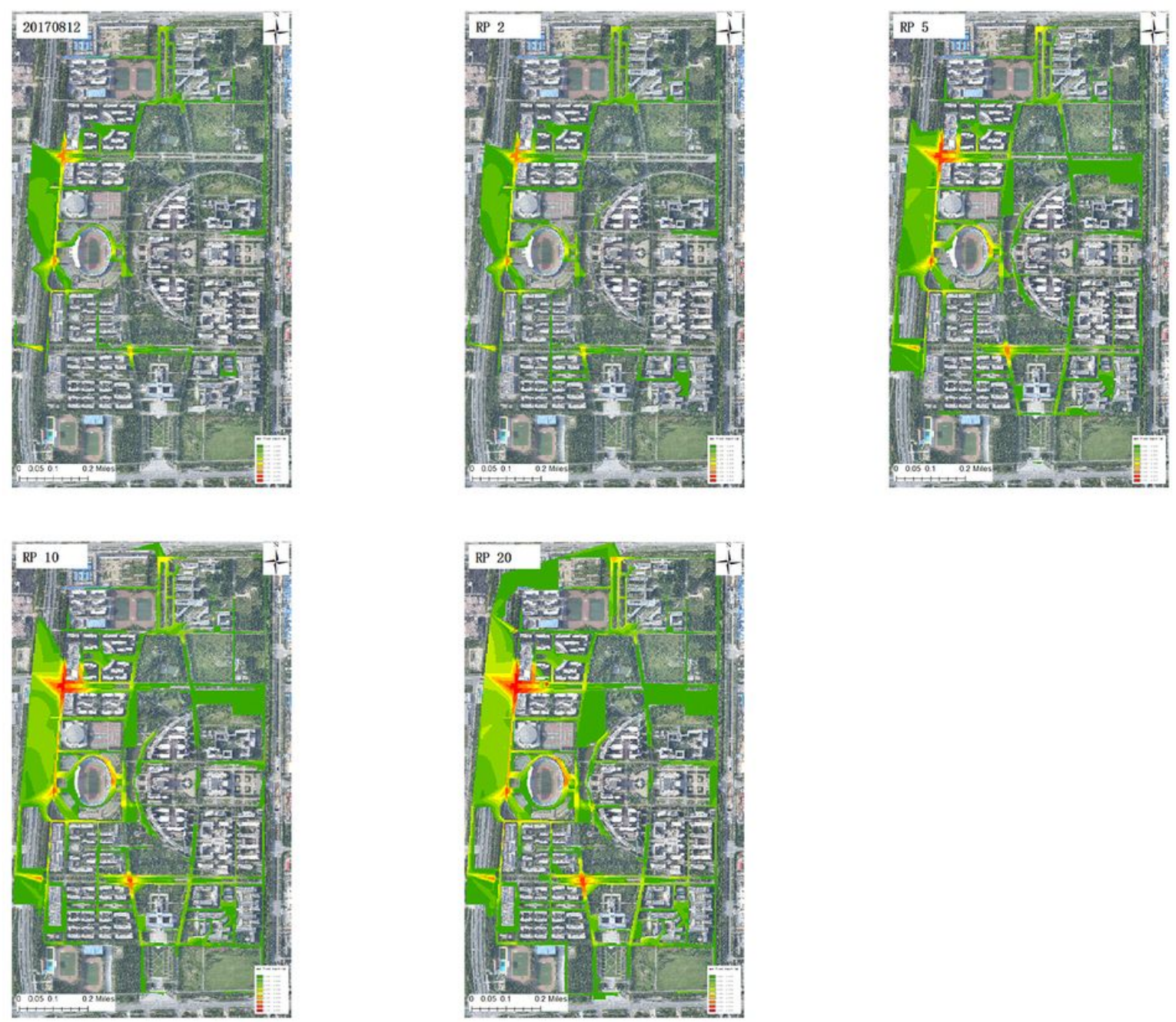

\section{Figure 9}

Verification results: Stationarity assumes maximum floodwater depth maps for RP 2, 5, 10, 20 and the maximum floodwater depth map on August 12, 2017 

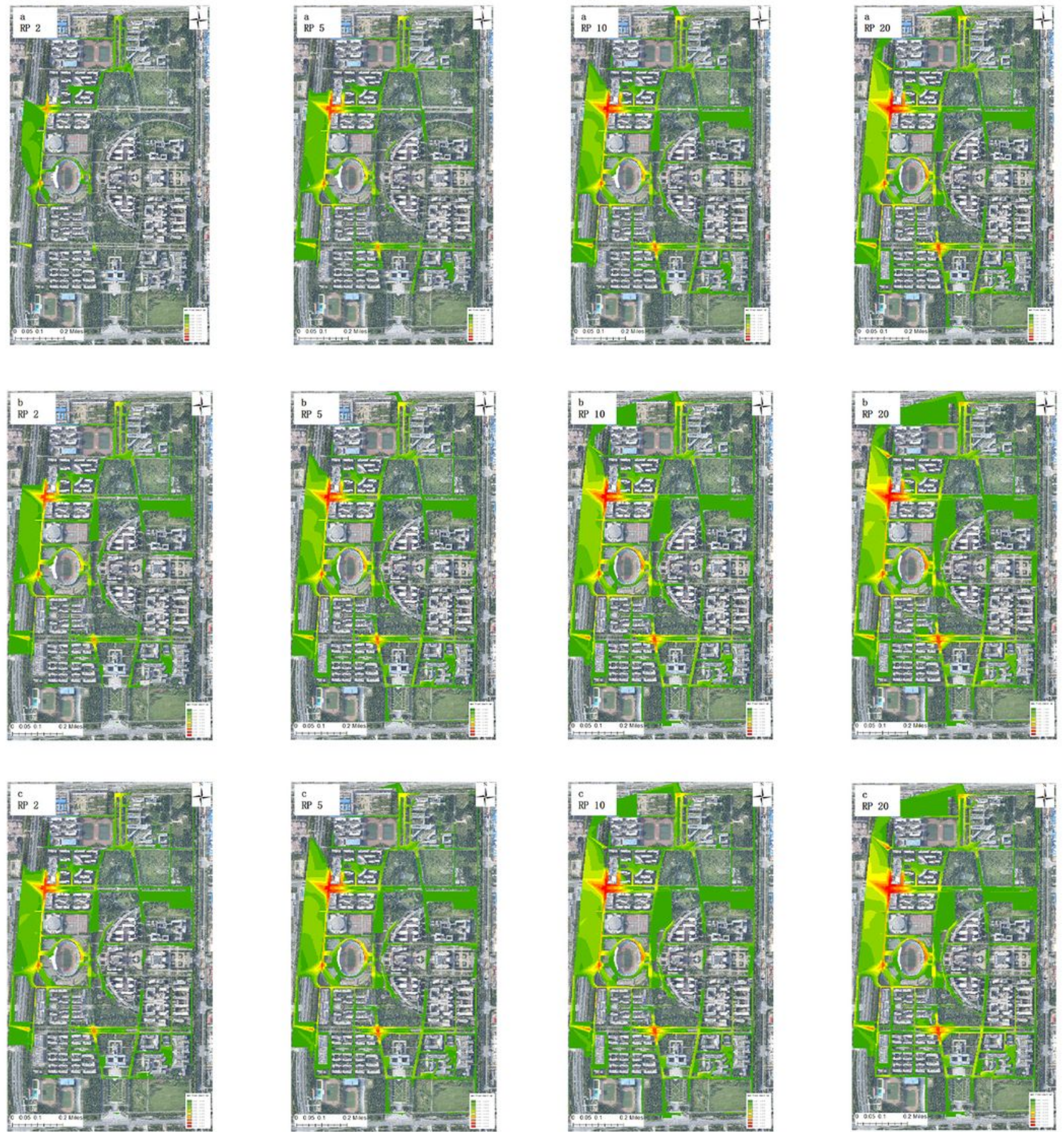

\section{Figure 10}

Maximum floodwater depth maps for RP 2, 5, 10, 20 under three scenarios of non-stationarity assumption 


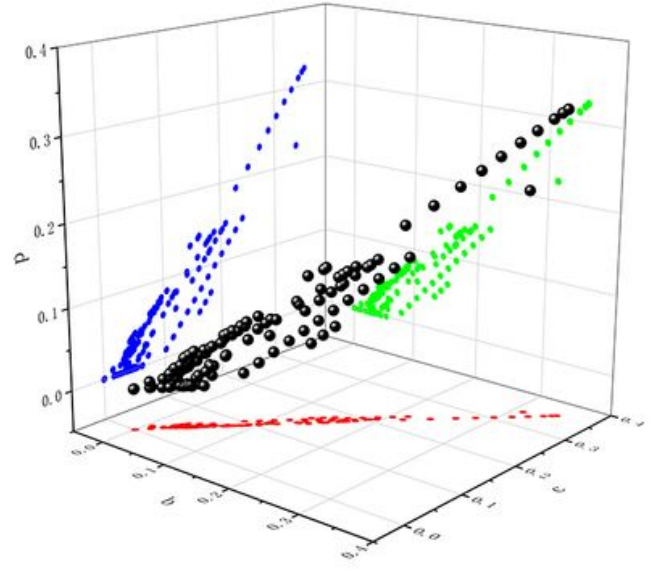

RP 2

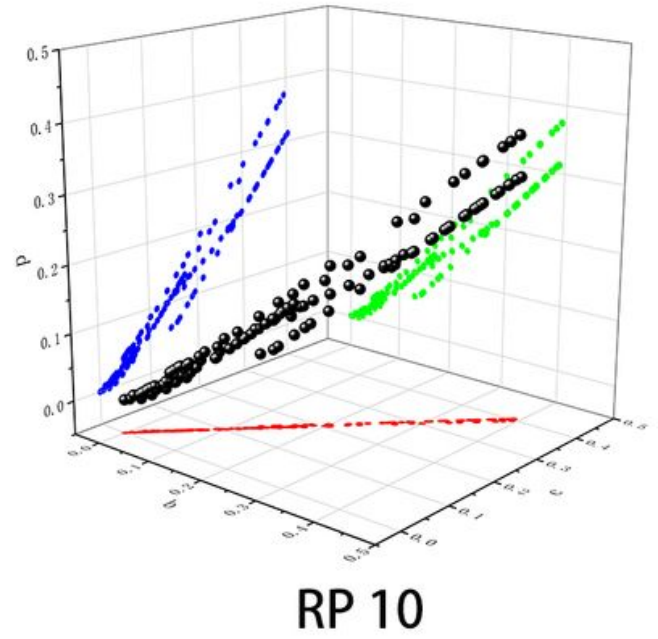

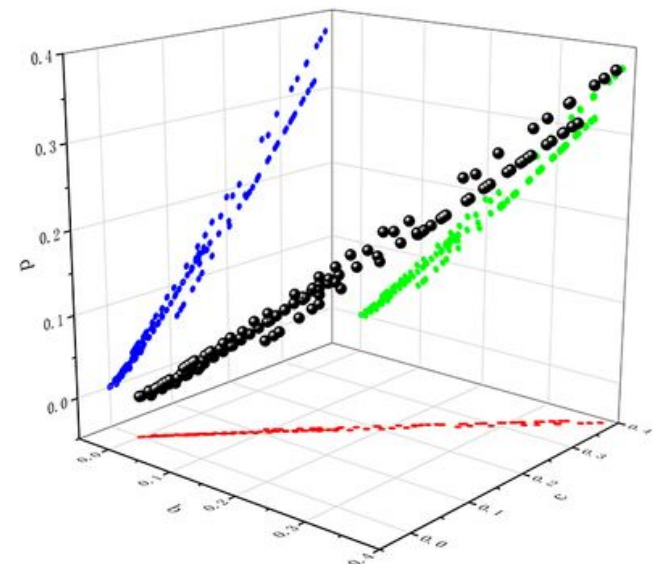

RP 5

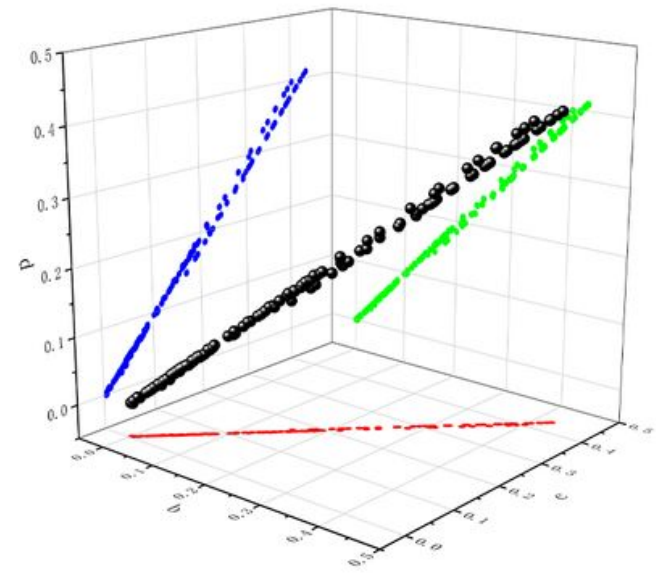

RP 20 unit: meter

Figure 11

Comparison of maximum flood depth of three scenarios 

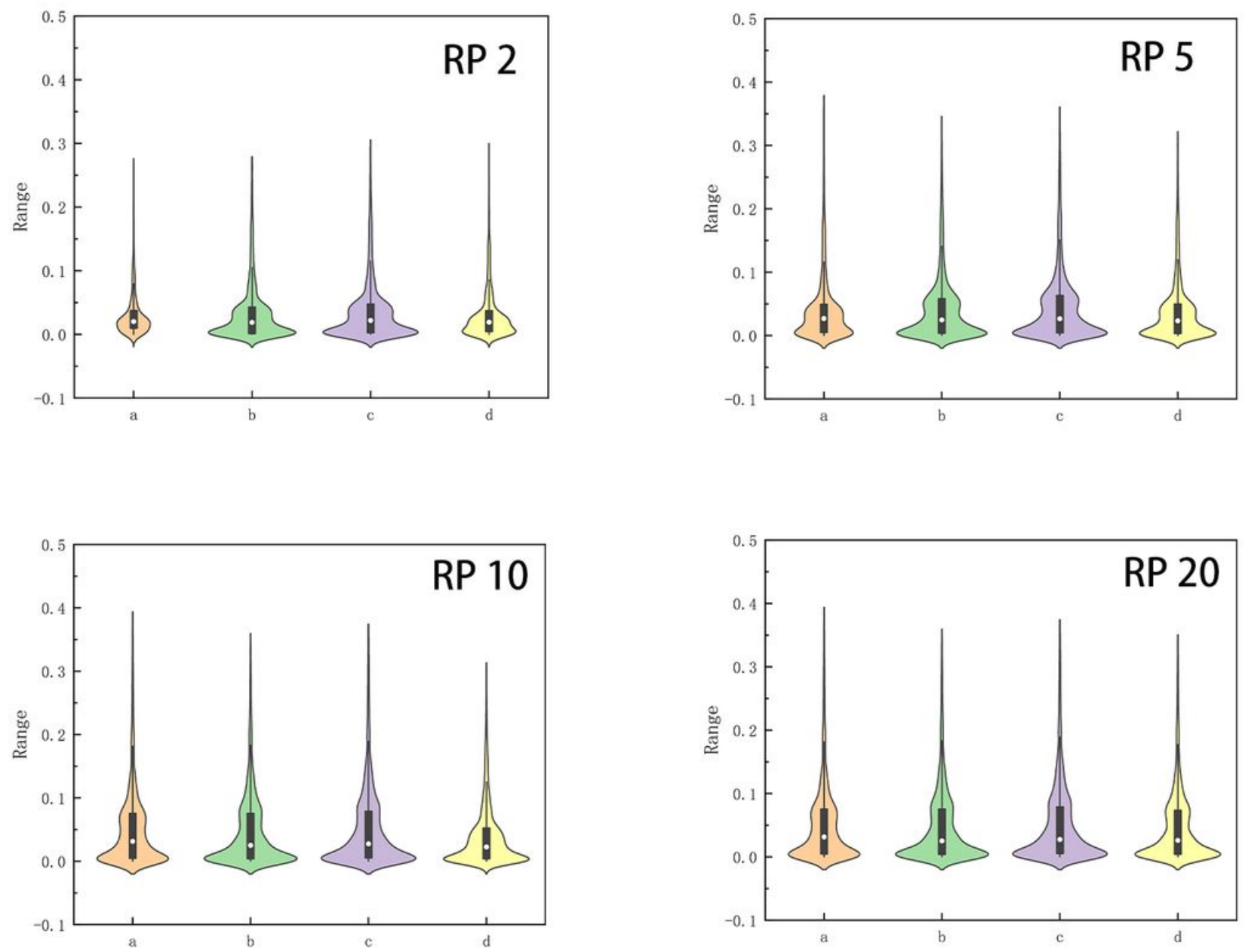

Figure 12

Comparison of maximum flood depth distribution in four scenarios 


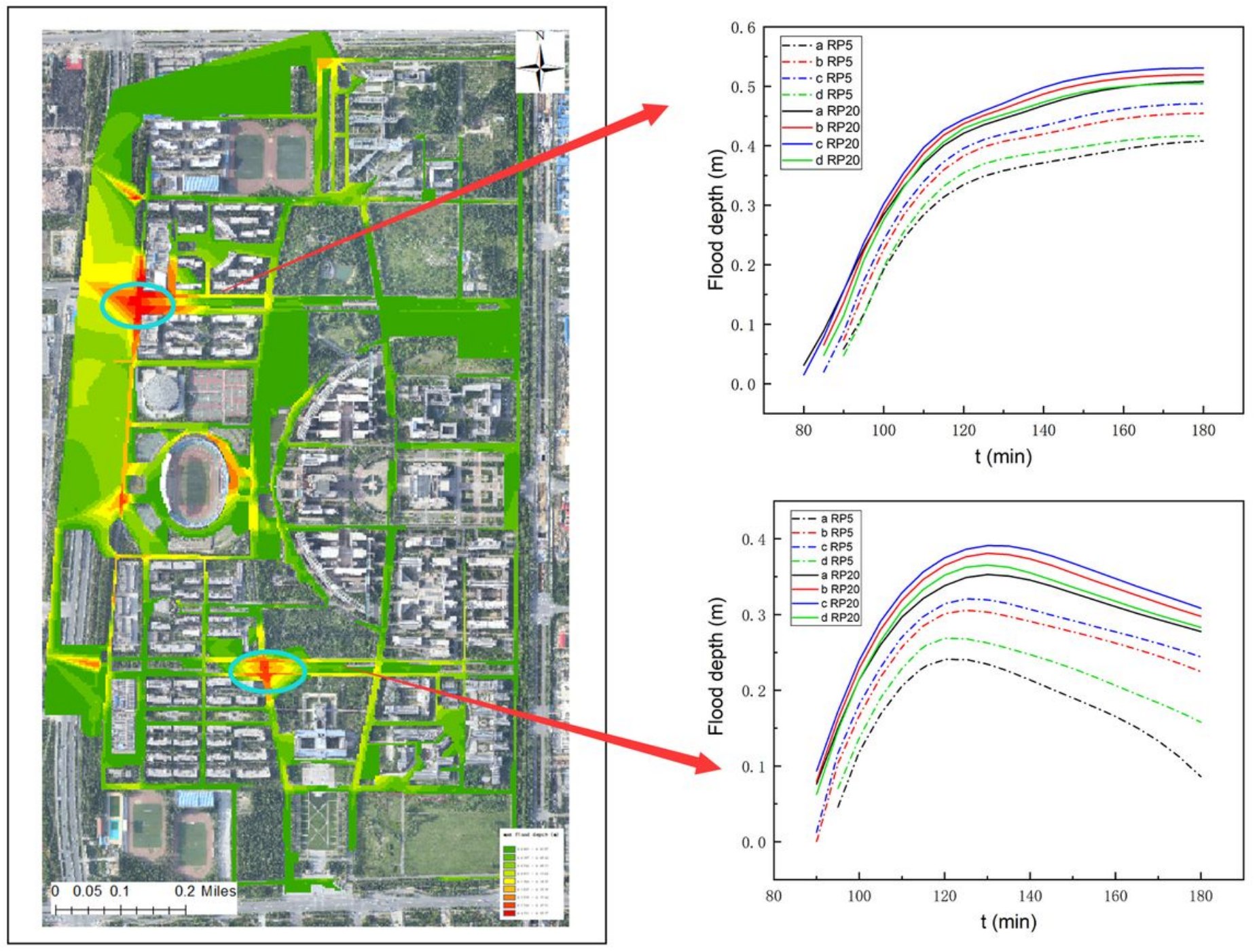

Figure 13

Comparison of detailed water accumulation processes in four scenarios 